University of Louisville

ThinkIR: The University of Louisville's Institutional Repository

Electronic Theses and Dissertations

$8-2020$

\title{
The Nigerian-American immigration experience: overcoming adversity through resilence.
}

K. Chinwe Idigo

University of Louisville

Follow this and additional works at: https://ir.library.louisville.edu/etd

Part of the Counseling Psychology Commons, and the Multicultural Psychology Commons

\section{Recommended Citation}

Idigo, K. Chinwe, "The Nigerian-American immigration experience: overcoming adversity through resilence." (2020). Electronic Theses and Dissertations. Paper 3510.

https://doi.org/10.18297/etd/3510

This Doctoral Dissertation is brought to you for free and open access by ThinkIR: The University of Louisville's Institutional Repository. It has been accepted for inclusion in Electronic Theses and Dissertations by an authorized administrator of ThinkIR: The University of Louisville's Institutional Repository. This title appears here courtesy of the author, who has retained all other copyrights. For more information, please contact thinkir@louisville.edu. 
THE NIGERIAN-AMERICAN IMMIGRATION EXPERIENCE: OVERCOMING ADVERSITY THROUGH RESILIENCE

\author{
By \\ K. Chinwe Idigo \\ B.A., Temple University, 2006 \\ M.S., Loyola College in Maryland, 2008
}

A Dissertation Submitted to the Faculty of the College of Education and Human Development of the University of Louisville In Partial Fulfillment of the Requirements for the degree of

Doctor of Philosophy in Counseling and Personnel Services

Counseling Psychology

Department of Counseling \& Human Development

University of Louisville

Louisville, KY

August, 2020 
Copyright 2020 by K. Chinwe Idigo

All rights reserved 

THE NIGERIAN-AMERICAN IMMIGRATION EXPERIENCE: OVERCOMING ADVERSITY THROUGH RESILIENCE

\author{
By \\ K. Chinwe Idigo \\ B.A., Temple University, 2006 \\ M.S., Loyola College in Maryland, 2008
}

A Dissertation Approved on

May 11, 2020

by the following Dissertation Committee

Dissertation Chair
Laurie McCubbin, $\mathrm{PhD}$

Lisa Hooper, Ph.D.

Amanda Mitchell, Ph.D.

Ahmad Washington, Ph.D. 


\section{ABSTRACT \\ THE NIGERIAN-AMERICAN IMMIGRATION EXPERIENCE: \\ ADVERSITY THROUGH RESILIENCE \\ K. Chinwe Idigo}

May 11, 2020

Nigerian-Americans are a fast-growing population in the United States, when compared to other immigrant groups. Despite growing numbers there is limited empirical research examining pathways that facilitate success among this immigrant population. This study addresses the dearth in literature by proposing and testing a modified $\mathrm{ABCX}$ model of family resilience among Nigerian-Americans. It is hypothesized that similar to other immigrant, and racial/ethnic minority groups in the United States, NigerianAmericans employ protective factors such as ethnic identity and resilience to buffer the effects of acculturative stress and perceived discrimination on well-being and psychological distress. Regression analyses suggest some consistency with the literature, with acculturative stress negatively predicting levels of psychological distress, and positively predicting psychological well-being, but not a significant predictor of relational well-being. Perceived discrimination was not a significant predictor of outcome variables in this study, ethnic identity was a positive predictor of relational well-being ( $\mathrm{p}$, 
but not a significant predictor of psychological well-being, and psychological distress.

Furthermore, resilience measured as an individual construct was predictive of psychological well-being, and relational well-being, but was not a predictor of psychological distress. However, resilience measured as a multidimensional construct was a significant predictor of all outcome variables in the present study. Exploratory moderated mediation in Amos indicate the ABCX model was unable to explain the relationships between study variables. Implications and study limitations are discussed. 
TABLE OF CONTENTS

PAGE

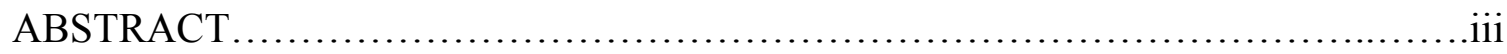

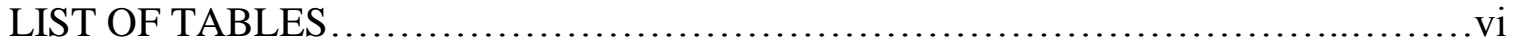

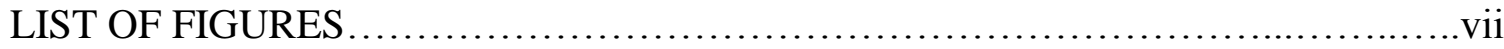

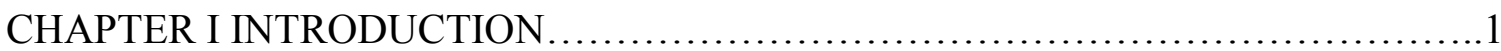

CHAPTER II METHOD .......................................................... 25

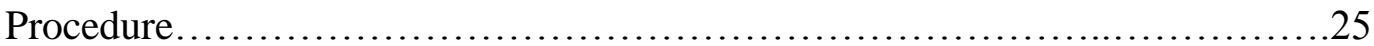

Recruitment.........................................................25

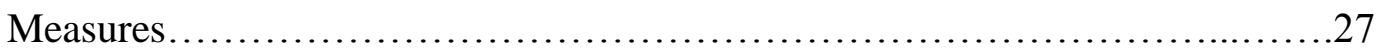

CHAPTER III RESULTS .....................................................

Preliminary Analyses................................................. 34

Primary Analyses..................................................36

CHAPTER IV DISCUSSION ................................................... 43

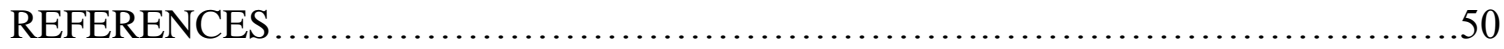

CURRICULUM VITA.................................................... 73 


\section{LIST OF TABLES}

TABLE

PAGE

1. Indicator of Each Last Matching Case as Primary.............................67

2. Correlations for Acculturative Stress, Resilience, Ethnic Identity and,

Perceived Discrimination..............................................68

3. Psychological Well-being, Relational Well-being, and Psychological

Distress as Dependent Variables.........................................69 


\section{LIST OF FIGURES}

FIGURE $\quad$ PAGE

1. Figure 1.1: The Double ABCX model.............................................70

2. Figure 1.2: The Double ABCX model with study variables......................................71

3. Figure 2.1: Exploratory moderated-mediation analysis........................72 


\section{CHAPTER I}

\section{INTRODUCTION}

As of $2014,13.3 \%$ of the United States population consisted of immigrants, with an estimated 1 million individuals moving to the United States annually to establish residency (Migration Policy Institute, 2016). It is projected that the United States immigrant population will continue to expand, and by the year 2065 immigration will account for $88 \%$ of the nation's population growth (Passel \& Cohn, 2017). Currently, approximately forty million of United States residents are foreign-born (Lopez \& Bialik, 2017). One of the fastest growing immigrant groups in the United States are individuals of African descent (Migration Policy Institute, 2012), with the largest group of African immigrants hailing from Nigeria (Pew Research Center, 2015). An estimated 228,000 Nigerian born individuals currently reside in the United States (Pew Research Center, 2015). This figure fails to account for first-generation Nigerian-Americans born in the United States, who are likely influenced by Nigerian and American cultures. Furthermore, some Nigerians are naturalized American citizens, and remain influenced by Nigerian values. It is estimated that in totality individuals with Nigerian ancestry account for roughly 750,000 of the United States population (Migration Policy Institute, 2015).

Given that immigration shapes the demographic and ever-changing cultural landscape of the United States, researchers, educators, healthcare providers and policy 
makers' knowledge and understanding of the Nigerian population is imperative to competent service provision. The purpose of this study is to ascertain the protective factors and pathways that lead to bonadaptation and maladaptation. In order to gain a deeper understanding of Nigerians living in the United States it is important to consider a contextual framework, inclusive of significant historical events that shaped Nigerian culture, politics and climate, while accounting for personal characteristics, and the effects of racial/ethnic identity, and culturally-based experiences such as racism and acculturative stress.

\section{Nigerian Culture}

Defining Nigerian culture is a complex task as prior to western invasion and subsequent colonization indigenes of the area did not function as a cohesive unit. Various groups occupied and co-existed in the space known as Nigeria today. Nigeria's heterogeneity of cultures consisting of various ethnic groups, languages, religion, food and style of dress still exist in present day. Much of these cultural norms stem from ancient civilizations from that region. Early historians trace the roots of ancient Nigerian civilizations to as early as 3000 B.C. (Nigerian: History, n.d.). However due to the civilization's reliance on oral culture and art as a form of cultural transmission, few written accounts exist on intricate details of these communities (Lamp, 2011). Despite the limited written history, it is widely known that several kingdoms existed in the northern and western parts of present-day Nigeria. These kingdoms consisted of a centralized government with a king presiding over the people (Iweriebor, 1982). While decentralized government oversaw most of the eastern region of present-day Nigeria. Elders, experts, representative government, and communal forms of government were in place. These 
communities were typically smaller than regions in the western hemisphere with centralized government (Iweriebor, 1982).

Accounts of daily lives of civilizations in ancient Nigerian were transmitted primarily through oral traditions. Critics of this form of cultural transmission assert this form of information sharing is prone to exaggerations and misinterpretations due to limitations of human memory (Essien, 1995). As a result, information garnered from these sources are deemed less reliable, and inaccurate depictions of history (Lang \& Mercier, 1984). However, Nigerians in the pre-colonial era employed complex systems to facilitate accurate transmission of cultural information. This is clearly demonstrated by the use of chants, songs, poems and proverbs as seen in the Yoruba ethnic group from western Nigeria (Adediran, 1983). Furthermore, empirical evidence suggests individuals of west African origin are more likely to accurately remember paragraphs and prose than their western counterparts (Ross \& Millsom, 1970). Therefore, oral accounts and traditions may in fact provide more accurate depictions and accounts of history and culture, than originally expected. The majority of literature on ancient civilizations and kingdoms in Nigeria draw from oral tradition and are likely to provide valuable insight into the history of Nigerian culture.

Records on pre-colonial life in Nigeria suggest sophisticated communities of hunters, farmers and fishermen (Essien, 1995). Refined skills such as weaving, blacksmithing, palm-wine tapping and salt making facilitated specialized industries, which enhanced trade with neighboring regions, and internationally (Essien, 1995; Kpone-Tonwe, 2001). These economic systems, which sustained pre-colonial Nigerians, were governed by a system of rules emphasizing and maintaining cultural values of the 
group (Amadi, 2000; Lovejoy, 1974). This suggests culture and social values were an important part of identity for some groups that are descended from pre-colonial Nigeria, and point to existing protective factors in place to thrive as a community.

An example of cultural events, and traditional rites and rituals that maintained the social fabric include the Yaa tradition of the Ogonni people in eastern Nigeria, which was a form of inauguration into society performed by elders to introduce younger citizens into society. This ceremony was a path to economic access and political privilege in Ogonni society, and in order to take part in the ceremony individuals must be deemed spiritually and physically fit (Kpone-Tonwe, 2001). This tradition suggest respect for elders and spirituality is a value among some Nigerian people. Additionally, maintaining social harmony was an important value to some Nigerians as evidenced by an emphasis on sharing and ensuring each person received a substantial portion. This practice was common among south eastern Nigerians who sometimes sacrificed efficiency to ensure the needs of each individual in the group were met, thereby maintaining social harmony (Amadi, 2000). As such, an inclusion of measures that account for community, and spirituality when assessing strengths of this sub-group is worth exploring.

The rituals and rites described in this section represent just a few of the various ceremonies and values that were significant components of pre-colonial Nigerian culture. Many pre-colonial societies in Nigeria strived for social harmony and balance, but also maintained a caste system excluding some members of society including women, foreigners and slaves from political processes (Amadi, 2000). However, there were also processes in place for male citizens to elevate their social standing, and gain access to privileges afforded to free citizens only. Various groups existed and evidence suggests 
intermingling of people and culture through marriage, religious rituals, cultural traditions, and economic trade, along with occasional conflicts related to land disputes (Okpeh, 2008). Therefore, when conceptualizing well-being and adaptation, the consideration of access to opportunity may also be an important element to capture.

Present day Nigeria was established by the British in 1914 as a singular group through an amalgamation of the predominantly Islamic northern region and predominantly Christian southern region (Okpeh, 2008). Several cultures and religions influence present day Nigerian culture through the years. For example, there are accounts of conversion to Islam in the northeastern region of present-day Nigeria as early as the eighth century, based on influence from northern African regions (Oloyede, 2014). Europeans primarily of Portuguese and English descent first set-up trading posts in Nigeria as early as the $14^{\text {th }}$ century (Adetugbo, 1978), with English and Portuguese becoming common languages in the Benin region around that time (Adetugbo, 1978). Furthermore, colonialism abolished traditional religious practices in Nigeria, with Christianity becoming widespread in the southern, western and eastern regions of the nation (Ibrahim, 1991). Colonization also introduced boundaries and demarcations that were reflective of the needs of colonizers as opposed to the cultural affiliations of indigenes. The institution of boundaries by foreign entities coupled with an imposition of foreign customs manifested culturally in the form of a hypersensitivity towards land ownership and cultural identity (Lenshie, 2014; Okpeh, 2008). Unfortunately, during the great depression, colonial powers further marginalized economic interests of indigenous Nigerians, leading to a loss of economic autonomy, and widespread poverty. Economic intervention designed to bolster western economies to the detriment of the local Nigerian 
economy in addition to an imposition of cultural practices plagued indigenous Nigerians (Ochonu, 2009).

Economic hardships during the great depression sparked criticisms of colonial rule (Ochonu, 2009), eventually leading to an end of colonial rule in 1960. Following the country's liberation, numerous efforts were made to establish and develop a national identity by emphasizing commonalities, while other groups aimed to assert their independence and emphasize qualities unique to their ethnic groups. Important facets of Nigerian culture include a description and identification of themes evident across several ethnic groups. Through these various transformations in governance, leadership and structure of the area, ethnic identity has remained a theme central to the Nigerian experience, despite efforts at nationalism (Attah, 2013). Making ethnicity a construct that may an important role in regard to the Nigerian-American experience.

\section{Immigration in the United States}

The United States has experienced several waves of immigration since its inception (Passel, 2011). Four major categories are: The colonial period, the nineteenth century, the twentieth century and immigration post 1965 (Batalova, \& Terrazas, 2013). The majority of Nigerians currently residing in the United States are part of the post 1965 immigration wave (Migration Policy Institute, 2015). Each new wave of immigration involves unique challenges, influenced by a myriad of factors including demographic variables such as race, ethnicity, religion and socio-economic status (Grambs, 1983).

Initially immigration into the United States beginning in the colonial period was relatively seamless, with a lack of government restrictions surrounding this process 
(Rubin, 1966). During the colonial immigration period, the government required labor workers to execute projects aimed at improving the country's infrastructure (Grambs, 1983; Totten, 2008). As a result, the government provided support, and access to English language lessons to facilitate the transition from immigrant to working citizen of the United States (Alba et al., 2009). Furthermore, during this period voluntary immigrants were largely racially homogenous hailing from western Europe, similarly to the politically dominant group in the United States at the time. There were few readily apparent differences between these groups. They both identified with an individualistic western culture, with cultural values from previous environments somewhat similar to cultural values of the new environment (Eisenstadt, 1953; Rubin, 1966). During these earlier waves of immigration into the United States, the goal and primary form of immigrant absorption was assimilation (Kavass, 1962). Assimilation occurs when an individual from a different culture makes contact with a new environment and takes on the cultural ideals, norms and values of the new group (Schachter, 2016).

Legislation in support of immigration during the colonial era includes The Naturalization Act of 1790, allowed only a "free white person, being of good character, and living in the United States for two years" to apply for citizenship (Naturalization Act of 1790). This law excluded several groups, including involuntary immigrants, mainly African-American slaves, Asian-Americans, and indigenes of the United States from access to the naturalization process, and benefits of citizenship (Horton, 1998; Sohoni, 2007). Furthermore, as global exploration became more commonplace, the type of immigrant to the United States grew more varied culturally and racially. The change in the demographics of typical immigrant populations resulted in a change in immigrant 
absorption efforts, and a classification system based on physical attributes. More antiimmigration laws were created targeting individuals from ethnic/racial groups differing from the white majority, coupled by a reduction of government supported immigration absorption efforts (Eisenstadt, 1953). Examples include the Chinese Exclusion Act of 1882, which restricted immigration of Chinese laborers into the United States. Legislation that was in stark contrast to the country's previous stance, where immigrants from western Europe were given language lessons, and offered jobs and sometimes even land.

A change in immigrant population and absorption efforts conjointly led to disparities in income and educational opportunities. It also created a visible "other" resulting in immigrants existing on the margins of society. Assimilation was less of an ideal option as newcomers were unable to quietly integrate into mainstream society due to physical attributes in contrast to the limited conceptualization of being "American" that was commonplace, as well as cultural differences such as collectivistic values over individualistic values. Similar to immigrants to the United States of the late $18^{\text {th }}$ century and $19^{\text {th }}$ century, Nigerian immigrants and first-generation Nigerian-Americans bear physical characteristics and cultural norms that differentiated them from mainstream United States citizens and thus, negotiate their identity on the margins of society (Balogun, 2011). As such, exploring the effects of ethnic identity, and perceived discrimination through their acculturation process, is likely to shed valuable insight into their experience.

Current immigration laws govern three distinct types of immigrants (Passel \& Fix, 1994). The laws that govern immigration include: (a) Immigration for work and 
educational purposes; (b) immigration for humanitarian purposes such as the absorption of asylum seekers and refugees, and (c) illegal immigration (King, 1983; Passel \& Fix, 1994). However, despite the complexity of immigration in the United States, much of the discourse around immigration focuses on illegal immigration (Passel \& Fix, 1994). An initial wave of Nigerians relocating to the United States was part of an initiative spear headed by the Nigerian government to provide its' citizens with the training and skill sets required to occupy positions requiring technological expertise. Promising young men received scholarships to attend Institutes of higher education in the United States. Following their tenure, many sought permanent residency through marriage, and employment sponsorship due to economic instability in Nigeria (Ette, 2012). This form of integration into American culture shaped the Nigerian narrative of immigration. For example, education is the primary mode of immigration into the United States for the immigrants from the Igbo ethnic group of Nigeria (Reynolds, 2002).

Nigerian-Americans became a distinct ethnic group in the United States in the 1980s when the U.S. Census Bureau provided estimates of the Nigerian population in the country. At that time roughly 25,000 individuals with Nigerian ancestry resided in the United States (Migration Policy Institute, 2015). This figure has grown at higher rates than most immigrant groups, with a sharp increase after the year 2000 (Pew Research Center, 2015). Two pieces of legislation that may have influenced the influx of Nigerian immigrants include: The Refugee Act of 1980 and the Diversity Visa Program passed in the 1990s (Pew Research Center, 2015). As of 2017, Nigeria is the largest exporter of students from sub-Saharan Africa to the United States, and is ranked seventeenth as a source of international undergraduate students in the United States (United States 
Embassy in Nigeria, 2012). Nigerian immigrants currently integrate into the United States with limited support from the government. Additionally, they hold a racial/ethnic identity distinct from the majority of the population. Exploring stressors that may impact Nigerian immigrants is likely to increase understanding of their psychological health. Given the history of Nigerians, and their growing population in the United States, it would be important to understand their acculturation process, possible exposure to discrimination, and its effects on their mental health.

\section{Acculturation and Acculturative Stress}

Human beings are dynamic and adaptable beings whose habits and behaviors change in an effort to adapt to their environment. Therefore, as Nigerians immigrate to the United States a shift in cultural values, and characteristics based on adjusting to the way of life in the United States is likely to occur. This change process also known as acculturation is defined as a change in values, beliefs and customs that occur following contact with a new environment, in order to adapt in a way that maximizes the chance of survival (Berry, 2002). Acculturation is a transformation that occurs following cultural contact (Birman et al, 2013; Okafor et al., 2012). Acculturation requires a minimum of two distinct cultures and an interaction between these two cultures which results in a fundamental shift in cultural expression (Obasi \& Leong, 2010).

Stressors affiliated with immigration and adaptation to culture is coined acculturative stress. Acculturative stress (e.g., hardships that are a result of adaptation to a new environment) influences a number of negative outcomes such as physical and mental health complications (Bai, 2016). Furthermore, there is evidence of a robust negative correlation between acculturative stress and positive outcomes such as well- 
being and life satisfaction in the literature (Jibeen, \& Khalid, 2010). This relationship exists among immigrants of Hispanic and Asian descent to the United States, and international students (Liu et al., 2016). Additionally, evidence in support of change in dietary practices, and health are also predictive of acculturative stress among NigerianAmericans (Daramola, \& Scisney-Matlock, 2014). Meta-analytic evidence supports the aforementioned relationship, with higher levels of acculturative stress correlating with poorer mental health among a sample of Latinos (Rodriguez, 2007). However, research on the effects of acculturation/acculturative stress on the mental health and well-being of Nigerian-Americans remains limited.

The predictive relationship of acculturative stress on immigrant health and wellbeing calls for further understanding of the wide-reaching effects of acculturative stress, and an analysis of how it relates to Nigerian-Americans. It is likely that a portion of Nigerian immigrants enter the United States through educational opportunities and programs. International students in the United States are notably at-risk for mental health complications (Wong, 2015). Furthermore, psychological distress remains prevalent among participants of refugee resettlement programs (Kim, 2016). Given the empirical support for these relationships, consideration of these associations among NigerianAmericans is likely to yield a more robust picture of this group's mental health and wellbeing.

\section{Perceived Discrimination}

As Nigerians adjust to American culture, an added component includes adjusting to the role of holding a racial/ethnic minority status, including navigating meanings affiliated with being Black in the United States. Black-Americans have shorter life 
expectancies than their White-American peers (National Vital Statistics Report, 2016) and are at higher risk of developing life-threatening conditions, including heart disease and stroke in comparison to White Americans (National Institute of Health, 2010). In addition to physical stressors and vulnerabilities associated with a Black racial identity, there are also social vulnerabilities members of this group contend with including experiences of racism and discrimination ranging from subtle microaggresions to overt forms of discrimination. Studies suggest African-born immigrants are not exempt from the experiences of discrimination Black-Americans have endured for several decades. African immigrants who experience discrimination are at risk for maladaptive coping behaviors including alcohol use (Tran et al., 2010) and physical and mental health outcomes such as increased risk for high blood pressure (Ryan, et al., 2006), and lower levels of self-esteem (Bourguignon et al., 2006). There remains a gap in the literature focused explicitly on experiences of discrimination among Nigerian-American immigrants and how this in combination with acculturative stress may impact NigerianAmericans' health and well-being.

Nigerian-Americans may experience acculturative stress and racially based discrimination for the first time in the United States. However, statistics show they are likely to attain financial success and security despite vulnerability for acculturative stress and stressors related to discrimination. Nigerian-Americans surpass the general population in achievement related to education, socio-economic status and employment (Migration Policy Institute, 2015), and remain one of the most educated immigrant groups in the country (Azeez, 2012; Smith, 2015). Given this level of attainment despite vulnerability to significant stressors, an exploration of protective factors may provide 
insight into the adaptation process for Nigerian-Americans, and their use of protective factors to buffer the effects of stressors on their mental health. Attah (2013) argues that Nigerians used ethnic identity to buffer the stressors affiliated with colonialism. However, Nigerian-Americans use of ethnic identity as a potential buffer from immigration related stressors in the United States (e.g. acculturative stress and perceived discrimination) remains unexamined in the literature.

\section{Ethnic Identity}

Ethnic identity is an extensively researched protective factor across various populations. It is prevalent across various disciplines of psychology as a multifaceted process inclusive of group affiliation, group affirmation, exploration, values and behaviors. Individuals explore various aspects of their cultural heritage by immersing themselves in cultural activities, prior to ascribing personal meaning to these aspects of their identity (Phinney, 1996; Phinney, 1989). Ethnic Identity is developed through an exploration process which is typically triggered by a crisis that makes ethnicity salient. This leads to an increased awareness of ethnic identity, and typically leads to exploration, and integration of ethnic values (Phinney, 1996).

Ethnic identity is a central part of self-concept among racial and/or ethnic minorities (Roberts et al., 1999). Individuals identify with their ethnic group to varying degrees, and the relevance of ethnic identity may differ (Phinney,1996). The importance of ethnic identity to self-concept may be situational and event-specific (Sellers et al., 1998). Higher levels of ethnic identity are more common among individuals who have explored their ethnic identity (Yip, 2014). Although some individuals may also commit to an identity without exploration (foreclosure), and accept and commit to group 
membership based on information from authority figures (Phinney, 1989). Rites and rituals discussed in earlier sections of this paper suggest ethnic practices, are an integral part of the Nigerian identity. Additionally, as Nigerian-Americans hold a dual minority identity based on race and ethnicity, patterns established among other minority groups may reflect a portion of this group's experiences A parallel of note, as a strong sense of ethnic identity is correlated with general well-being (Mohanty, 2013; Rivas-Drake et al., 2014), higher levels of self-esteem (Mohanty, 2013), self-efficacy (Jaret \& Reitzes, 2009) and social competence (Tran \& Lee, 2010). It is linked to a number of positive outcomes for racial ethnic minorities and immigrants (Berry et al., 2006). For example, ethnic identity correlates positively with increased levels of global self-esteem among a sample of Latino and Black adolescents (Phinney et al., 1997; Rhea, \& Thatcher, 2013). Furthermore, an established sense of ethnic identity was predictive of career decidedness among Black and Asian college students, which is indicative of successful adaptation (Duffy, \& Klongaman, 2009; Hooper et al., 2012). Ethnic identity has also been negatively correlated to mental illness and negative outcomes including eating disorders (Rhea, \& Thatcher, 2013), and depression (Hooper et al., 2012). In summary, ethnic identity is an important protective factor among racial ethnic minorities, as also shown by a meta-analysis by Smith \& Silva (2011), and it is worth exploring whether this relationship holds for Nigerian-Americans.

Ethnic identity also serves as a protective factor against the negative effects of discrimination (Ai et al., 2014; Pascoe \& Smart-Richman, 2009; Romero et al., 2014). Unfortunately, ethnic identity also has some deleterious effects, as individuals with stronger ethnic identity are more likely to perceive discrimination (Hall \& Carter, 2006; 
Pascoe \& Smart-Richman, 2009), which is associated with higher levels of discrimination distress (Lee \& Ahn, 2013; Pascoe \& Smart-Richman, 2009). However, they are able to cope with the effects of discrimination through group affiliation and maintain higher levels of life satisfaction (Stronge, et al., 2016). Nigerian-Americans may hold an immigrant identity, as well as a racial ethnic minority identity. As such, exploring the manifestation of ethnic identity for Nigerian-Americans and whether this variable remains a protective factor against the effects of discrimination and acculturative stress on well-being and psychological distress, is likely to bolster support for this variable as a protective factor with this population. Given the potential role of ethnic identity as a protective factor, understanding the likelihood of employing this protective factor is a valuable endeavor.

\section{Resilience}

Resilience is a construct that accounts for the ability to overcome hardship and stressors, and function at an adaptive level despite obstacles. Given the outcomes in economic and educational achievement for Nigerian-Americans, a resilience framework can shed light on the unique trajectories and processes of adaptation to U.S. culture within this population. Experiences of acculturative stress predict various forms of negative health effects, including poorer physical health and psychological distress (Zvolensky et al., 2016). However, despite Nigerian-Americans' membership in groups who are typically at-risk for lower levels of educational and financial achievement, Nigerian-Americans tend to thrive economically and educationally. Windle (2011), defines resilience as a dynamic process whereby individuals utilize a wide range of individual, communal, and social resources to navigate and manage stress and trauma. 
This process may vary across the lifespan, and resources utilized are specific to the stressor at hand. Individuals who are considered resilient have overcome some form of stressor and/or adversity (Windle, 2011). However, in addition to positive qualities and potential traits that help an individual adapt to stressors, resilience also involves the ability to seek out social support, family support and community resources effectively, in order to overcome barriers and adapt successfully in spite of adversity (Werner, 1993). Resilience processes are complex, and intricately interwoven (Fonagy et al., 1994). Resilience can consist of biological predispositions as well as, behavioral, relational, and emotional habits that are transmitted trans-generationally (Fonagy et al., 1994). Resilience goes beyond the individual's ability to function adaptively despite hardship, but also explores the significance of social resources as a buffer to stressors (Bottrell, 2009).

In addition to demographic markers such as gender and culture discussed in previous paragraphs, comprehensive definitions of resilience also consider developmental stages, and ways in which individuals draw on coping skills deemed adaptive based on their current developmental stage (Southwick, et al., 2014). Individuals who are considered resilient are also able to construct meaning from stressful experiences, and learn life lessons that promote positive adaptation (Werner, \& Brendtro, 2012). Findings from a longitudinal study by Werner (1993) suggests some adults despite being categorized as "at-risk," and experiencing various adversity through their adolescent years, possessed the capacity to adapt positively given accessibility to opportunities such as education, vocational training, and exposure to religion and/or spirituality of some form. Additionally, resilience in adulthood is related to positive affect, buttressed by 
social support, providing empirical support for the dynamic process of resilience in adults (Ong et al., 2009).

Nigerian-Americans are affiliated with groups considered "at-risk," and adapt educationally and financially. Considering ethnic identity's potential role to buffer effects of acculturative stress and perceived discrimination, and the process of resilience in maintaining bonadaptation, it is useful to determine if resilience influences NigerianAmerican's ability to utilize ethnic identity as a coping resource against stressors. Resilience has been linked to a number of positive outcomes including increased mental health, self-esteem and persistence (Aloba et al., 2016; Campbell-Sills \& Stein, 2007; Notario-Pacheco et al., 2011). It is also negatively linked to maladaptive outcomes including depression, anxiety, psychological distress and deviant behaviors (Aloba et al., 2016; Asanter \& Meyer-Witz, 2014; Coates et al., 2013). The relationship between resilience and the outcomes mentioned above has received empirical support among various samples including immigrants to the United States, Nigerian students, community members, and adult populations (Aloba et al., 2016; Liu et al., 2015). These relationships also hold when measuring resilience with instrument that focus on various forms of resilience, such as individual traits, and use of community and social resources.

Resilience is a complex process with nuanced presentations based on biological, psychological and social factors across various domains (Southwick et al., 2014). Advancements in measurement have influenced the conceptualization of resilience (Windle, 2011). Therefore, relationships noted in the literature will be discussed in tandem with measurement of the construct. This study will employ the use of the Connor Davison Resilience Scale (CD-RISC), an instrument widely used in the United States. 
This scale is based on the stress, coping and adaptation framework of resilience, which looks at the response to stress, and use of coping resources (Cosco et al., 2016). The instrument has been used to establish relationship between resilience and sleep quality among a sample of students in Spain (Notario et al., 2011), psychological health among Nigerian nursing students, and a diverse student sample (Aloba et al., 2016; CampellSills \& Stein, 2007; Notario et al., 2011). It also correlates with physical health in a sample of Nigerian nursing students (Aloba et al., 2016), and self-efficacy among a Vietnamese immigrant sample (Nguyen et al., 2015).

Despite popularity of the aforementioned measure of resilience, there may be some challenges associated with this instrument. The CD-RISC was developed as a fivefactor scale, measuring resilience as a construct that encompasses personal competence, high standards and tenacity; trust in instincts, tolerance of negative affect, and strengthening effects of stress; positive acceptance of change, and secure relationships; control; and spiritual connections (Connor, \& Davidson, 2003). However, further analysis of the CD-RISC indicates the five-factor structure fails to hold up theoretically and statistically (Campbell-Sills, \& Stein, 2007). Furthermore, the five-factor structure lacks empirical support among many ethnic groups and depicts some gender-based variability (Peng et al., 2014). A revised version of the scale, a ten-item unifactor instrument, has the benefit of brevity, and disposes of the faulty five-factor structure. However, some evidence of gender-based variety remains, with men scoring higher on this measure than women (Aloba, et al., 2016; Campbell-Sills \& Stein, 2007; Peng et al., 2014). Possible explanations for the gender-based variability in scores on this resilience measure may be item-specific. The CD-RISC utilizes items that hone in on individual competence 
(Windle, 2011). Other measures of resilience suggest men tend to score higher on aspects of resilience related to personal competence, while women tend to score higher on components of resilience related to eliciting and providing social support (Friborg et al., 2003). The Resilience Scale for Adults (RSA) will be used in conjunction with the CDRISC, to address the multidimensionality of resilience from other conceptual and theoretical models.

The RSA is based on the tripartite resilience framework, which conceptualizes resilience as the degree of dispositional attributes, family cohesion/warmth, and external support systems (Werner, 1993). The RSA measures these constructs across five factors: Personal competence, social competence, social support, family coherence, and personal structure (Hjemdal et al., 2001). An additional factor, structured style and the use of thirty-three items was recommended, following research examining the psychometric properties of the instrument. (Friborg et al., 2003). The benefit of this scale is the inclusion of social, community, and familial supports into the conceptualization of resilience, making it a suitable additional measure to the CD-RISC, by addressing gender disparities, and including multiple dimensions of resilience such as personal, interpersonal, and community factors, thereby addressing values related to social harmony, a value deemed important among Nigerians. However, despite this measure's apparent theoretical fit for the Nigerian-American population, the RSA is not as widely used in the United States therefore including the ten-item unifactor CD-RISC is prudent.

Overall, there has been a sharp increase in the Nigerian-American population since the new millennium. Scientific literature has yet to catch-up with this immigration trend. Nigerian-Americans are mostly immigrants who hold a racial/ethnic minority 
status, thus vulnerable to acculturative stress and perceived discrimination. Recent immigrants to the United States are more likely to endorse depression and anxiety than their peers native to the United States (Bas-Sarmiento et al., 2017). No studies were found examining specifically the mental health of Nigerian-Americans. Given the potential relationship between immigrants and first-generation Americans and mental health issues, exploring factors that may influence mental health could help in supporting Nigerian-Americans living in the United States. Research has provided some empirical evidence that ethnic identity can help buffer the effects of perceived discrimination among racial and ethnic minorities. Additionally, research indicates that resilience measures have predicted higher levels of positive adaptation and well-being among several immigrant groups. However, there remains a paucity of research exploring both of these unique stressors, ethnic identity and resilience and their respective impact on mental health among Nigerian-Americans.

\section{Theoretical Framework}

As indicated previously empirical literature on this population remains in its nascent stage, with limited established relationships between specific factors for this study. Despite this challenge, literature does suggest an exposure to stressors and protective factors can promote well-being among immigrants. For example, a systematic review of Latino immigrant families noted behaviors indicative of resilience (Cardoso, \& Thompson, 2010). On average Nigerian-Americans have been exposed to historical stressors related to political and economic instability, the Atlantic slave trade, colonization, and wars (Ayokhai et al., 2013; Imbua, 2013). A study of Native Americans noted a relationship between historical stressors and increased levels of psychological 
stress, a relationship that is maintained inter-generationally (Arizala, 2012). Furthermore, Nigerian-American immigrants experience a separation from their homeland, and to varying degrees separation from family members. Nigerian-Americans are also tasked with integrating into a new environment and negotiating a new identity, which often times involves adjusting to a racial minority status and potentially experiencing overt and implicit racism. However, it does not appear that the Nigerian-American story is simply one of strife. Research findings suggest successful outcomes and potential healthy adaptation despite numerous hardships. As such, a theoretical framework that considers this group's exposure to stressors, protective factors and potential positive adaptation can assist in providing a more coherent narrative of Nigerian-Americans' experiences in the United States.

A model that accounts for the use of coping resources to overcome hardship is the Double ABCX model of resilience. Developed in a familial context, this model explores ways in which families exposed to stressors employ a myriad of resources and coping mechanisms to overcome hardships and successful adaptation (McCubbin, 1979). The model also accounts for cognitive appraisals family members make related to stressful situations (McCubbin, \& Patterson, 1983). Despite its inception in the family stress literature, this model serves as a useful framework for evaluating adaptation to stress among immigrants. The "A" component of the model includes the pile-up of stressors which can include trauma, life events and everyday hassles. The "B" component evaluates the use of resources to help manage stressors, and prevent severe disruption in functioning. "C" involves the ability to make meaning out of the stressors, and make changes to meet the demands of the events or trauma, and " $\mathrm{X}$ " is the degree to which a 
crisis inhibits, has no effect on, or improves normative functioning (van Breda, 2001); see Figure 1.1. In summary, the Double ABCX model is a framework of overcoming exposure to significant stressors and the mechanisms that can promote or hinder wellbeing.

The Nigerian-American experience lends itself to conceptualization from the framework described above. For example, the process of immigration can include trauma, significant life events such as immigration and multiple stressors thus the "A" factor in the Double ABCX model. In fact, immigration-related stress is a well-established concept in the literature among various immigrant groups (Torres \& Wallace, 2013; Yakhnich, 2008). Additionally, stressors related to integrating into a new environment, and navigating a minority status are added stressors Nigerian-Americans and immigrants must contend with. Framing these new experiences as stressors that require adaptation allows for an exploration of the impact of these new experiences on Nigerian-Americans without the assumption of pathological outcomes. One might hypothesize that known resources against the effects of discrimination such as ethnic identity may function as a resource or protective factor for Nigerian-Americans, accounting for the " $\mathrm{B}$ " in the Double ABCX model. The "C" factor, which accounts for cognitive appraisals related to stressors, and changes instituted to adapt to the stressors, may also be relevant for this group's adaptation process. Therefore, an individual's perception of their degree of personal and social competence, and use of community resources which are components of resilience, account for this portion of the model. Additionally, exploring levels of resilience based on Friborg et al.'s (2003) five-factor model can shed light on the type of resources and potential coping mechanisms most important and employable to this group. 
While "X" simply looks at the group's ability to function adaptively, after the exposure to stressors, resources, and ability to employ these resources to overcome new challenges. Figure 1.2 below shows the Double ABCX model as conceptualized for this study.

A major advantage of the Double ABCX model of resilience is the comprehensive evaluation of exposures to ecological stressors, and the active use of a range of resources to maintain equilibrium. Most resilience researchers concur that resilience is a process, thereby the use of a model that addresses the dynamic interplay between the person and environment may be better able to account for the complexity of this process. However, a challenge with this model involves difficulty discerning between resources, and appraisal of coping. Specifically, factor "B" and "C" of the model. A flexible and non-linear application of the model, allows for this model to be used in a way that is representative of real world experiences.

\section{The Present Study}

The purpose of this study was to gain insight into factors that predict well-being among Nigerian-Americans. There is strong support for the relationship between acculturative stress, perceived discrimination and well-being and psychological distress. Therefore, it was hypothesized that "The negative relationship between acculturative stress and well-being and psychological distress established in the literature, would also exist among Nigerian-Americans," with the null hypothesis- there is no difference on psychological distress or well-being based on acculturative stress (Hypothesis 1).

Hypothesis 2 looks at whether perceived discrimination will predict lower levels of wellbeing and higher levels of psychological distress, therefore the null hypothesis- there is no difference on psychological distress or well-being based on acculturative stress was 
tested. The $3^{\text {rd }}$ hypothesis examines whether ethnic identity will predict higher levels of well-being and lower levels of psychological distress, by testing the null hypothesisthere is no difference on psychological distress or well-being based on ethnic identity. Hypothesis 4 looks at perceived resilience's ability to predict higher levels of well-being, and lower levels of psychological distress among Nigerian-Americans, by testing the null hypothesis- there is no difference on psychological distress and well-being based on perceived discrimination.

In addition to ethnic identity and resilience serving as predictive variables, there is also support in the literature for their ability to influence the effects of stressful events and experiences on well-being. Ethnic identity is higher among individuals who have explored their ethnic background, and exploration is typically in response to crises related to ethnic identity. As such, the fifth hypothesis in this study was the effect of acculturative stress, and discrimination on well-being and psychological distress is mediated by ethnic identity. Given the protective qualities of resilience the final hypothesis (hypothesis 6) will test whether the mediated effect of acculturative stress, ethnic identity and perceived discrimination on well-being and psychological distress is moderated by resilience. 


\section{CHAPTER II}

\section{METHOD}

\section{Procedures}

This study utilized an exploratory design to test hypothesized relationships between variables. The investigator employed two primary modes of data collection, specifically online recruiting, and fliers. To qualify for the study participants must be 18 or older, self-identify as Nigerian, reside in the United States, and have at least one parent of Nigerian descent. International students with at least one parent of Nigerian ancestry were also included in the study, with the goal of recruiting a diverse Nigeria sample. Exclusion criterion was individuals of Nigerian ancestry who do not consider the United States their primary residence.

\section{Recruitment}

Participants were recruited through listservs for organizations that cater to people of Nigerian and/or African descent residing in the United States. Additionally, fliers inviting individuals to participate in the study were circulated on college campuses, local Nigerian and African restaurants, as well as community centers, churches and local businesses catering to this group. To increase contact, the examiner used snowball 
sampling to extend beyond immediate points of contact by asking individuals who received recruitment literature, to share with their network. Snowball sampling is particularly effective when contacting a group that is relatively unknown (Waters, 2015). Participants were invited to participate in a twenty-five to thirty minute online survey. Each completed survey qualified participants to enter a drawing to earn one of two gift cards to Amazon valued at $\$ 50$ each. At the end of the survey, participants were asked if they would like to be entered into the drawing, and to provide their e-mail so they could be contacted if they are selected for the prize. Following recruitment termination, two names were randomly drawn from the sample size using random.org, and winners were notified via e-mail about their winnings. The examiner deleted all e-mail addresses after receiving confirmation from amazon that gift cards were retrieved.

Data collection was conducted over a six-month period. Initial recruitment began by targeting churches, grocery stores, and religious organizations that serve Nigerians living in the United States, in the New Jersey area, which is local to the examiner. The examiner also posted on personal social media, as well as social media groups for Nigerian-Americans, and Africans living in the United States. Additionally, contact was made with influential figures in these groups such as, religious leaders and business owners to introduce them to the study, and to ask them to forward study information to their constituents. Nonprofit organizations dedicated to serving Nigerians living in the United States also received study invitations. For example, leaders of Aguleri Foundation of North America (AFNA), Anambra State Association, United States of America (ASAUSA), Redeemed Christian Church of God, and Four Square Gospel Church all received invitations to participate in the study and share with members. Over the course of six 
months, over 50 organizations, serving Nigerian-American communities across the United States received a survey invitation.

\section{Measures}

Demographic sheet. Demographic data were obtained via self-report. Study participants were asked to provide demographic data including age, ethnic group, education level, income-level, and gender. To determine geographic location, respondents were asked to include the name of the state they reside in. Finally, respondents were also asked whether they are first generation immigrants to the United States or first generation born in the United States. Given the novelty of this group to the United States, it is unlikely that second generation Nigerians born in the United States will meet age-based inclusion criteria, and that data were not collected.

Acculturative stress. The Acculturative Stress Scale for International Students (ASSIS) was utilized as a measure of acculturative stress (Sandhu \& Asrabadi, 1994). The ASSIS is a 36-item measure, which assesses stressors related to acculturation among international students. Sample items on this measure include "I feel guilty to leave my family and friends behind," "Others don't appreciate my cultural values," and "I feel uncomfortable to adjust to new values." Respondents are asked to rate each item using a 5-point Likert scale ranging from 1 to 5, with 1 being strongly disagree and 5 being strongly agree. Scores on this measure are determined by summing all the items giving scores a range of 36 to 180 . Higher scores indicate a stronger degree of acculturative stress. The measure consists of 7 factors, and provides a total score as an indicator of level of acculturative stress. Internal consistency reliability was also established at the subscale level as follows; value conflict ( 4 items, $\alpha=.67$ ), identity threat ( 5 items, $\alpha=$ 
.67 ), cultural competence ( 5 items, $\alpha=.78$ ), homesickness ( 5 items, $\alpha,=.66$ ), selfconfidence ( 5 items, $\alpha=.67$ ), opportunity deprivation ( 5 items, $\alpha=.67$ ), and rejection (5 items, $\alpha=.78$ ), suggesting acceptable reliability (Liu et al., 2016). Results from a Confirmatory Factor Analysis (CFA) indicate good model fit based on the above factor structure Root Mean Square Error of Approximation (RMSEA) $=0.04$, Comparative Fit Index $(\mathrm{CFI})=0.93$, and Goodness of Fit Index $(\mathrm{GFI}))=0.91($ Liu et al, 2016). The ASSIS shares 49\% variance with the Center for Epidemiologic Studies- Depression Scale (CES-D), indicating convergent validity (Constantine, Okazaki \& Utsey, 2004). The ASSIS has been used among a community sample of Nigerian immigrant women (Daramola \& Scisney-Matlock, 2014). A total score was used for this study, with a Cronbach's alpha of .94 with the current sample.

Perceived discrimination. To measure perceived discrimination, the examiner used the Expanded Everyday Discrimination Scale (EEDS). The EEDS is an enhanced version of the Everyday Discrimination Scale, which was developed among a sample of predominantly European-Americans, and African-Americans (Williams et al., 1997). An item was added to the original scale to create the EEDS (Williams, et al., 2008). The final product is a 10-item scale that measures individuals' perceptions of unfair treatment based on various aspects of their identity. Participants are asked to indicate how often they have had experiences such as "you are treated with less courtesy than other people are," and "people act as if they think you are not smart," and "you are followed around in stores.” Respondents indicate whether they have experienced such events on a 5-point Likert scale ranging from 0 to 5 with 0 being "never," to 5 being "almost everyday." Total sum scores range from 0 to 50, with higher scores reflecting higher levels of 
discrimination. There were positive correlations between the EDS and the Kessler Distress Scale, Expressed Anger Scale, and the Suppressed Hostility Scale (.17 - .19, p > .001), indicating convergent validity. Divergent validity was established through negative correlations between the EDS and the General Diabetes Knowledge Scale p > .02 (Gonzales et al., 2016). No explicit validity studies for the EEDS were found. However, the EEDS predicted stress, and mental illness in a South African population, suggesting some convergent validity (Moomal et al., 2009). This sample had a Cronbach's alpha of .92 on this scale.

Ethnic identity. The Multigroup Ethnic Identity Measure-Revised (MEIM-R) was used to assess ethnic identity. The MEIM-R is a 6-item scale used to measure ethnic identity based on Marcia's theory of Ethnic Identity Development (Phinney \& Ong, 2007). Sample items on the MEIM-R include "I have a strong sense of belonging to my group," and "I have often done things that will help me understand my ethnic background better." Respondents rate items based on a 5-point Likert scale ranging from 1 (strongly disagree) to 5 (strongly agree). Total sum scores range from 5 to 30 , with higher scores indicating stronger levels of ethnic identity. On average the measure has a Cronbach's alpha of .88 (Herrington et al., 2016)). The measure consists of two, 3-item factors which gauge the degree of exploration of, and commitment to one's ethnic identity status (Phinney \& Ong, 2007). Results of a CFA suggest the MEIM has excellent model fit, with an adjusted goodness of fit index (AGFI) of .96, a CFI of .98, and an RMSEA or .04 , indicating construct validity (Phinney \& Ong, 2007). This study used the total score of the MEIM-R, with a Cronbach's alpha of .82 for the study sample.

Resilience. The Connor-Davidson Resilience Scale-10 (CD-RISC-10) and The 
Resilience Scale for Adults (RSA) were utilized as measures of resilience. The CD-RISC10 is an assessment of resilience derived from the Connor-Davidson Resilience Scale (CDRISC) (Campbell-Sills \& Stein, 2007). The CD-RISC is a 25-item assessment of resilience that measures the construct across five domains; "personal competence, high standards and tenacity," trust in instincts, tolerance of negative affect," positive acceptance of change and secure relationships," "control," and "spiritual influences" (Connor \& Davidson, 2003). The CD-RISC-10 is a shortened version of the CD-RISC, and is a 10-item unifactor measure of resilience (Campbell-Sills \& Stein, 2007). Sample items include "Able to adapt to change," "Coping with stress can strengthen me" and "Can handle unpleasant feelings." The measure consists of a 5-point Likert scale ranging from 0 to 4 , with 0 being "not true at all," and 4 being "true nearly all the time." Total sum scores range from 0 to 40, with higher scores indicating higher levels of resilience (Campbell-Sills \& Stein, 2007). The CD-RISC has been used cross-culturally as a measure of resilience. Construct validity was established by using the CD-RISC-10 to moderate the relationship between retrospective reports of childhood maltreatment and current psychiatric symptoms $\mathrm{R}=.51, \mathrm{R}^{2}=.31, \mathrm{~F}$ $(3,126)=19.00$. Results suggest preliminary evidence for validity of the measure (Campbell-Sills \& Stein, 2007). The current sample had a Cronbach's alpha of .86.

The Resilience Scale for Adults (RSA) (Friborg et al., 2003) is a 33-item scale measuring resilience. The RSA includes items such as "In our family we are loyal towards each other," There are strong bonds between my friends," and "I easily adjust to new social milieus." Respondents rate these items using a 5-point Likert scale ranging from 1 (strongly disagree) to 5 (strongly agree) (Hjemdal et al., 2015). Total sum scores range from 33 to 231 with higher scores indicating higher levels of resilience. The RSA consists of six 
subscales including, personal competence (6-items, $\alpha=.75$ ), social competence (6-items $\alpha$ $=.72$ ), family coherence (6-items $\alpha=.81$ ), social support (7-items, $\alpha=.70$ ), planned future (4-items $\alpha=.68$ ) and personal structure (4-items, $\alpha=.87$ ) (Friborg et al., 2003). Concurrent validity for the RSA was established by correlating the RSA negatively with the Hopkins Symptom Checklist $(-.43, \mathrm{p}<.05)$, and positively with the Social Coherence Scale $(.61, \mathrm{p}$ $<.05)$. The total RSA score, and all subscales except the personal structure subscale were correlated as expected. The five subscales excluding personal structure correlated with the Hopkins Symptom Checklist as follows- personal competence $-.59, \mathrm{p}<.05$, social competence $-.24, \mathrm{p}<.05$, family coherence $-.12, \mathrm{p}<.05$, social support $-.26, \mathrm{p}<.05$ and planned future $-.43, \mathrm{p}<.05$. The subscales correlations for the Social Coherence Scale were $.55, .38, .30, .44$ and .49 all at $\mathrm{p}<.05$ respectively (Hjemdal et al., 2011). This study utilized total scores, with a Cronbach's alpha of .91 for the study sample.

Psychological distress. As a measure of psychological distress respondents were asked to fill out the General Health Questionnaire-12 (GHQ-12). The GHQ-12 is a widely used brief measure that assesses for mild mental illness among community and clinical populations. This measure consists of 12 items. Respondents answer items such as "Have you recently felt capable of making decisions" "Have you felt constantly under strain?" and "Have you been feeling unhappy or depressed?" They are asked to rate these items using a 4-point Likert scale ranging from 0 to 3 with 0 indicating "better than usual" and 3 representing "much less than usual." The sum total score is used for this scale ranging from 0 to 36 , with higher scores indicating higher levels of psychological distress (Makanjuola et al., 2014). The GHQ-12 has been correlated with the Beck 
Hopelessness Scale $(r=.641, \mathrm{p}<.001)$, indicating construct validity (Aloba et al., 2016). This scale had a Cronbach's alpha of .89 for the current sample.

Well-being. To study well-being two measures will be utilized: Ryff's Psychological Well-being Scale (PWB), and the Relational Well-Being II (RWB II). The PWB is a widely used tool which measures psychological well-being across 6 domains (Autonomy, Environmental Mastery, Personal Growth, Positive Relations, Purpose in Life, and Self-acceptance). The measure consists of 42-items, which include items such as "I have a sense of well-being and purpose," and "In general, I feel confident and positive about myself." Respondents rate these items using a Likert scale ranging from 1 to 6 with 1 indicating they "strongly disagree" with the statement, and 6 indicating they "strongly agree" with the statement (Ryff, 1989). This instrument has been used to predict the prevalence of mental illness suggesting divergent validity (Abbott, et al., 2006). This study will use a total score, which has a Cronbach's alpha of .91 for the study sample.

The RWB II was also used as a measure of well-being. The RWB II is a 21-item instrument that measures well-being from a collectivistic framework (McCubbin et al., 2013). Participants rate items such as "I have the confidence to face hardships" and "I have the money to pay bills." Utilizing a 4-point Likert scale ranging from "none of the time" to "all of the time." Higher scores indicate increased levels of well-being. Discriminant validity for the RWB II was established using measures of physical and mental health. There was a statistically significant difference in RWB II scores for individuals scoring extremely high and low on the measure of mental health, $\mathrm{t}(158)=-$ $6.407 \mathrm{p}=.0001$. Additionally, individuals on the extremely high and low scales on the 
measure of physical health, also had scores significantly different, $t(136)=-4.33 p=$ .0001, suggesting discriminant validity. (McCubbin et al., 2013). This study utilized a total score, which had a Cronbach's alpha of .85 for the present sample. 


\section{CHAPTER III}

\section{RESULTS}

\section{Preliminary Analyses}

To test the hypotheses the initial step was to conduct preliminary analyses in SPSS to compute descriptive statistics, and test assumptions. Preliminary analyses will be followed-up with primary analyses.

Data cleaning. A total of 154 participants submitted the survey, of that number, 1 respondent identified as White/Caucasian, and was therefore ineligible for the study, and was deleted from the sample. The examiner then ran an analysis for duplicates based on IP address. Initial analysis showed 3 duplicates based on IP address alone. See Table 1 below: However, further analysis showed 1 case was likely unique, and this participant varied in response styles, and demographic markers in meaningful ways, such as age, responses, ethnic group, and response IDs, as such an additional 2 cases were deleted from the sample. For a total of 3 out of 154 cases deleted, bringing the final sample size to 151 .

In order to maximize sample size, the examiner utilized multiple imputations to address missing data. Multiple imputation is a robust method to utilize when the amount 
of missing data in a sample is under 5\%, and data is missing at random (Jakobsen et al., 2017). A frequency analysis in SPSS showed and 54 out of 26,274 (.21\%) of all values in the sample were missing, 39 out of the 174 (22.41\%) study variables had missing data, and 13 out of 138 (8.61\%) of participants had missing data. Furthermore, analysis in SPSS showed the most common pattern was all participants responded to all items, and data lacked monotonicity. There were no other significant patterns detected in this sample, suggesting data is missing at random, making multiple imputations an ideal method to handle missing data.

Power analysis. The investigator conducted a power analysis to determine minimum sample size to run the model. The final sample size following recruitment and data cleaning was 151 . To increase study power total scores only were used for the RSA, reducing degrees of freedom in the model. The use of total scores, will reduce observed variables from 19 to 8 . The degrees of freedom will likely be less than 8 , since the degrees of freedom are typically the number of known variables minus free parameters (Kenny, 2011). With 7 as the degrees of freedom, the required sample size to utilize structural equational modeling based on a g-power analysis will be 160 . However, since the final sample was 151, the investigator utilized structural equational modeling on an exploratory basis only.

Descriptive statistics. Statistical Package for the Social Sciences (SPSS) was also used to calculate demographic data of participants. Of the 151 participants, 93(61.69\%) identified as Igbo, $47(31.13 \%)$ as Yoruba, 3(2\%) as Efik, 2(1.32\%) as Edo, 2(1.32\%) as Esan, $1(.66 \%)$ as Ishan, $1(.66 \%)$ as Ibibio, $1(.66 \%)$ as Tiv, and 1(.66\%) as Yala, indicating sample size is reflective of individuals living in the south-eastern, and south- 
western regions of Nigeria. In terms of age, 144(95\%) out of the 151 participants responded to this item, with an average age of 40.01, a mode of 36, and a range of 19 to 76 in the study sample. For gender, 1(.66\%) person opted not to disclose this information, $65.6 \%$ of the sample identified as female, $32.5 \%$ identified as male and $1.3 \%$ identified as transgender male. All participants provided information on education level, and 37.7\% were college graduates, $36.4 \%$ held a master's degree, $21.9 \%$ a doctoral degree, $3.3 \%$ some college or community college, and .1\% of the sample holding a high school diploma. Participants represented 29 U.S. states and territories, with $40(26.5 \%)$ of the sample from Texas, 30 (19.9\%) from New Jersey, 16 (10.6\%) from New York, 10 (6.6\%) from Maryland, 9 (6\%) each from California and Kentucky, 3 (2\%) each from Pennsylvania, and Georgia, 2 (1.3\%) each from Arizona, Minnesota, and Ohio, and 1 (.7\%) each from Alabama, Arkansas, Washington D.C., Delaware, Florida, Iowa, Illinois, Louisiana, Michigan, Missouri, New Hampshire, Utah, Washington, and Wisconsin. All 151 participants responded to the item on citizenship status, with 104 (68.9\%) identifying as foreign born residents, who hold permanent residence or citizenship status, 37 (24.5\%) were born in the United States, and $10(6.6 \%)$ holding temporary visas with plans to secure permanent residency in the future.

\section{Primary Analyses}

To test the first four hypotheses proposed, the examiner utilized multiple regression analyses. In order to utilize regression as an analytical procedure, the data needs to meet certain assumptions (Field, 2009). These assumptions are data should have homogeneity of variance. However, when group sample sizes are equal a violation of this assumption, does not significantly affect the outcome of data (Field, 2009). Total sample 
data were used for all analyses, thereby meeting the assumption of homogeneity of variance. Other assumptions include that data should be observed independently, and participants were asked to respond to the questionnaire independently in order to meet this assumption. The sample should also have homoscedasticity, with data and errors being normally distributed. Normality of data is influenced by sample size, with a sample size of fifty, estimating to normal data (Stevens, 2007). The sample size for this study is 151 , increasing the chances of meeting the aforementioned assumption. Additionally, with multiple regression a test of multicollinearity to ensure the variables are accounting for unique variance is also required (Field, 2009; Stevens, 2007). Results below show a correlation of $r=.57$ between acculturative stress and perceived discrimination. The correlation matrix for variables from model 2 which include individual resilience, multidimensional resilience, and ethnic identity were also tested. As seen below individual resilience and multidimensional resilience had a correlation of $r=$ .37 , individual resilience and ethnic identity had a correlation of $r=.20$, and multidimensional resilience and ethnic identity had a correlation of $r=.22$, suggesting no issues related to multicollinearity with the study sample.

All assumptions for regression were sufficiently met, and to prepare data for hypothesis testing, data were standardized to ensure consistency. Therefore, the examiner converted variables to $\mathrm{Z}$ scores. The first two hypotheses were tested using a forced entry regression, as there is no evidence in the literature to suggest perceived discrimination is a stronger predictor of well-being and psychological distress, than acculturative stress or vice versa. When this is the case a forced entry method is recommended (Field, 2009). The next two research questions were also tested via forced entry multiple regression 
analysis as well. The examiner tested the null hypothesis e.g. there is no significant difference on psychological distress and well-being based on ethnic identity and resilience.

To test hypotheses 1 and 2 Perceived Discrimination, and Acculturative Stress were entered into a regression model. The null hypothesis e.g. there is no significant difference in well-being as measured by the PWB and RWB, and psychological distress, as measured by the GHQ-12 based on perceived discrimination and acculturative stress was tested. Results of the regression shows Perceived Discrimination was not a significant predictor of psychological distress $F(1,148)=.28, \beta=-.01, \mathrm{p}=.60$, relational well-being $F(1,148)=.96, \mathrm{p}=.34$, or psychological well-being $F(1,148)=$ $.02, \mathrm{p}=.59$. Acculturative stress was a significant predictor of psychological distress $F(1$, $148)=5.40, \beta=.23 \mathrm{p}<.05$, showing a positive correlation between the acculturative stress and psychological distress. The $\mathrm{R}^{2}$ of .07 suggests this regression model accounts for $7 \%$ of the variance in psychological distress. Acculturative stress was also a significant predictor of psychological well-being $F(1,148)=3.11, \beta=-.19, \mathrm{p}<.05$, indicating a negative relationship between acculturative stress, and psychological wellbeing. In this model, the $\mathrm{R}^{2}$ of .04 suggests acculturative stress accounts for $4 \%$ of the variance in psychological well-being. However, acculturative stress was not a significant predictor of relational well-being $F(1,148)=3.50, \beta=-.15, \mathrm{p}=.14$.

To test hypotheses 3 and 4 resilience and ethnic identity were entered into a second regression model. The null hypotheses- resilience as measured by the CD-RISC, and the RSA were not significant predictors of psychological distress and well-being, and ethnic identity as measured by the MEIM are not significant predictors of psychological 
distress and well-being. Resilience as measured by the CD-RISC was a significant predictor of psychological well-being $F(1,147)=52.19, \beta=.18, \mathrm{p}<.05$, showing a positive relationship between the CD-RISC and psychological well-being. It was also a significant predictor of relational well-being $F(1,147)=30.54, \beta=.32, \mathrm{p}<.05$, also showing a positive relationship between the two variables, but not a significant predictor of psychological distress $F(1,147)=17.10, \beta=-.04, \mathrm{p}=.62)$. Resilience as measured by the RSA was a significant predictor of psychological well-being $F(1,147)=52.19, \beta=$ $.64, \mathrm{p}<.05)$, showing a positive relationship, it was also a significant predictor of a positive relationship with relational well-being $F(1,147)=30.54, \beta=.37 \mathrm{p}<.05$. The RSA also predicted psychological distress $F(1,147)=17.10, \beta=-.49, \mathrm{p}<.05$, indicating a negative relationship between the RSA and psychological distress. Ethnic identity was a significant predictor of a positive relationship with relational well-being $F(1,147)=$ $30.54, \beta=.14 p<.05$ ), but it was not a significant predictor of psychological well-being $F(1,147)=52.19, \beta=-.04, \mathrm{p}=.46$, and also not a significant predictor of psychological distress $F(1,147)=17.10, \beta=-.02, \mathrm{p}=.80$. Overall, the model had an $\mathrm{R}^{2}$ of .38 for relational well-being, suggesting this model accounted for $38 \%$ of the variance on that variable. For psychological well-being the model had an $\mathrm{R}^{2}$ of .52 , suggesting the model explains $52 \%$ of the variance in psychological well-being. Relational well-being had an $\mathrm{R}^{2}$ of .38 , which indicates the model explains $38 \%$ of the variance when relational wellbeing is an outcome variable, and lastly for psychological distress, the $\mathrm{R}^{2}$ was .26 which explains $26 \%$ of the variance of that outcome variable.

The goal of the multiple regression analyses was to establish empirical support and an impetus for organizing the model (Hopwood, 2007). However, due to limitations 
in sample size the fifth and sixth hypotheses were tested in an exploratory manner only (Serang et al., 2017). The examiner conducted a moderated-mediation analysis, utilizing variables found to be significant based on regression analyses. The first step was to combine outcome variables into a single variable called well-being. To achieve this latent factor, the examiner used SPSS to reverse z-scores for the variable measuring psychological distress, as psychological distress showed a negative correlation with psychological well- being $(r=.48)$, and a negative correlation with relational well-being $(r=.33)$. Then the variables were combined into a single variable. The examiner excluded perceived discrimination from the final model, since it was not a significant predictor in the regression model. Resilience as measured by the CD-RISC was also excluded from the analysis, as resilience as measured by the RSA was a more robust predictor of outcomes with this sample. The final model looked at Acculturative stress as the stressor and the independent variable, ethnic identity as the mediator, resilience as measured by the RSA as a moderator, and well-being as the outcome. This new model was used to test the null hypothesis: protective factors and cognitive appraisals do not influence the relationship between stressors, and well-being.

To prepare the data for analysis the examiner utilized $\mathrm{z}$ scores to standardize the independent variable, and moderator. The next step was to label pathways using a joint effect to detect interaction effects, and to do so the investigator created a path from the moderator to the mediator, and the mediator to the dependent variable. Finally, this effect was defined in Amos to estimate the moderated variable as a function of the mediator. The examiner tested a direct path between acculturative stress, and the outcome variable well-being. The examiner also tested a direct path from ethnic identity (the mediator) to 
well-being (dependent variable), and resilience as measured by the RSA (the moderator) to well-being as well. Additionally, moderating effects, and mediating effects were explored. To create the moderator, an interaction effect with acculturative stress, and resilience was created in SPSS, and the moderating variable was centered in SPSS to avoid multicollinearity. Finally, the model tested for a moderated mediation effect.

Data were uploaded from SPSS into AMOS, and a model utilizing the variables outlined above were entered into a model. Results show an insignificant model with no moderated mediation $\chi 2(0, \mathrm{~N}=151)=.00, \mathrm{p}=.248$. Other statistics used to test the model include a comparative fit index (CFI), and root mean square error of approximation (RMSEA). A CFI value greater than .95 indicates good model fit, and an RMSEA less than .05 also indicates good model fit (Klein, 2011; McDonald \& Ho, 2002). The model in the present study had an RMSEA of .31 indicating poor model fit, CFI of 1.0 which typically indicates good model fit. However, the degrees of freedom indicate a saturated model, and as such the CFI statistic is uninterpretable. These results indicate that based on study data, resilience does not moderate the path between acculturative stress and ethnic identity. Furthermore, results suggest no mediation in this model, indicating ethnic identity does not mediate the relationship between acculturative stress and well-being.

A secondary goal was to determine whether the direct paths, and moderating paths are statistically significant. The moderating effect was also insignificant $\mathrm{p}=.77$, suggesting resilience does not moderate the relationship between acculturative stress and well-being. In terms of the direct paths acculturative stress had a significant path to ethnic identity $\mathrm{p}<.05$, resilience also had a significant direct path to ethnic identity $\mathrm{p}<.05$, 
ethnic identity had a significant direct path to well-being $\mathrm{p}<.05$, acculturative stress also had a significant direct path to well-being $\mathrm{p}<.05$. 


\section{CHAPTER IV DISCUSSION}

Results from the study provide an intricate picture of resilience among NigerianAmericans. The demographic data obtained from this study suggest the study sample matched the profile of Nigerian-Americans provided by previous data. For example, participants in the study were highly educated in comparison to the general United States population. Furthermore a significant portion of the sample reported an income that is over the national average. In addition, similar to other immigrant groups, resilience was a significant predictor of psychological well-being (Ong et al., 2009), with resilience being positively correlated with relational well-being, and psychological well-being. Resilience measured as a multi-dimensional construct was also negatively correlated with psychological distress, but contradictorily when measured as an individual construct was not significantly correlated to psychological distress for this sample. This finding provides support for the use of a multidimensional theory of resilience to explain resilience, adaptation, and coping processes among Nigerian-Americans, based on the historical significance of ethnic norms, and community cohesion (Amadi, 2000).

Other findings consistent with the literature include the predictive quality of acculturative stress among this population. Similar to other immigrant groups, acculturative stress negatively predicted psychological well-being, and positively predicted psychological distress (Jibeen, \& Khalid, 2010). For Nigerian-Americans who 
have historically utilized community as a source of strength, and adaptation, separation from community of origin likely creates a disruption in well-being, and adaptation. However, acculturative stress was not significantly correlated with relational well-being, suggesting they may internalize relationships formed initially, and utilize it as a source of strength and coping. When it comes to ethnic identity, relational well-being was the only outcome variable of significance, suggesting relational well-being's unique relevance to this group. Given the importance of ceremonial rites and rituals to Nigerian-Americans, and social harmony based on historical accounts (Amadi, 2000; Kpone-Tonwe, 2001), it could be that when ethnic identity with this group is high, it fosters a greater sense of interpersonal and community wellness. Regardless of the reason for this relationship it is important to note that this measure provides additional insight into the experience of Nigerian-Americans, that may not be obtained from other measures of well-being which focus on individual constructs and traits.

Surprisingly, perceived discrimination was not a significant predictor of psychological well-being, psychological distress, or relational well-being in this study. This is inconsistent with previous findings in the literature (Tran et al., 2010), and it will be important to explore whether these findings can be replicated in other studies. Possible explanations might be the tendency for immigrants of Nigerian descent to incorporate experiences, culture, and heritage from country of origin into their identities, thereby minimizing the role and influence of racism, and negative connotations as opposed to African Americans who due to a history of slavery and systematic long-term racial injustice, are unable to do so (Okonofua, 2013). Other unexpected findings were the lack of correlation between ethnic identity, and psychological well-being, and psychological 
distress, as historically, these variables have been correlated among other immigrant groups (Mohanty, 2013; Rivas-Drake et al., 2014). Furthermore, the three outcome variables were expected to show consistent outcomes based on the literature. However, only resilience as a multidimensional construct, and perceived discrimination related to the outcome variables in a consistent manner, further highlighting the importance of utilizing constructs that also account for community and interpersonal elements when studying Nigerian-Americans.

Finally, although the moderated mediation was exploratory in nature, it is important to consider ways in which the proposed hypothesis was unsupported. The analysis lacked support for a moderated mediation, but it did highlight some interesting relationships that were not tested through regression analysis. For example, there was a direct path between ethnic identity, and resilience as a multidimensional construct, suggesting a relationship between these two variables, which is consistent with the literature (Romero et al., 2013), although the directionality of this relationship remains unknown. An additional finding from the model is the direct path between acculturative stress and ethnic identity.

\section{Strengths, Limitations, \& Future Directions}

This study is the first of its kind, that scrutinizes the experiences of NigerianAmericans as it relates to immigration, adaptation, and coping. A strength of this study is its ability to address questions pertaining to construct and measurement. By utilizing two measures of resilience, and two measures of well-being, this study provides insight into the importance of operationalizing a construct, and sheds light into the importance of cultural considerations when picking a measure for a study. Although this study is unable 
to determine why the RSA was a better predictor of outcomes in this study, it does suggest that the RSA may be a better detector of strengths within this population, and utilizing a construct which focuses solely on individual traits may provide an incomplete picture when studying Nigerian-Americans. Future research may explore whether this pattern remains consistent with Nigerian-Americans, and with other immigrant groups with more communalist and collectivist worldviews. Furthermore, relational well-being which is a new construct appears to hold some value when studying ethnic identity with Nigerian-Americans, and resilience as an individual, and multidimensional construct. It will be important to explore whether relational well-being manifests similarly with other populations, and further research comparing relational well-being to psychological wellbeing is likely to yield beneficial results.

Another strength of this study is its ability to address multiple constructs in a single study, and utilize concrete psychological tools to address complex theories of racial identity, ethnic identity, and resilience. Although the exploratory model did not hold, it is important to note that ethnic identity and resilience measured as a multidimensional construct were significantly correlated. There is some evidence of racial identity which is similar and distinct to ethnic identity being a predictor of resilience with African-American girls (Butler, et al. 2018). It seems that findings from the present study support this relationship. However, future research is warranted to fully explore how resilience manifests with racial identity and ethnic identity in a single study, which may provide further insight into the distinction between these two variables that are often conflated in the literature. Furthermore, resilience serving as an outcome predictor, but 
not a moderator of stressors may suggest immigrants with desirable character traits, and a solid social support network, are not immune to the effects of acculturative stress.

Additionally, this study is one of the few in the literature that examines NigerianAmericans as a group that is distinct from African-Americans, Caribbean-Americans, and immigrants to the United States from other African countries. It provides a framework, for future research to explore in further detail adaptation, and mental health functioning of this group independently. Furthermore, it sheds light on the aspects of NigerianAmerican immigrants' lives that are similar to, and different from the experiences of African-Americans. Future research should consider the common practice of consolidating immigrant groups from the Caribbean, and Africa into a group with African-Americans depending on the research question. Findings of this study suggest racism, and discrimination may be a more salient component of the African-American experience, than Nigerian-Americans. Research exploring whether the connection to a country of origin, provides an extended avenue to develop self, which makes racism a less salient component of the Nigerian-American experience is a reason for this difference between the aforementioned groups.

Despite the various strengths of this study, there were also some limitations to consider. For example, the examiner utilized a snowball sampling technique, which is recommended when studying sub-groups. However, there is always the question of whether the obtained sample is truly reflective of the entire Nigerian-American community, or a sample that is more reflective of the investigator's social group. It is important to note that majority of the sample shared an ethnic group similar to the examiner, and as such snowballing may have limited the sample. Additionally, there were 
no study participants from the northern region of Nigeria, and as such results from this study should be applied to that group with caution. It is also important to note that the examiner also identifies as Nigerian-American, and thus conceptualization of this study was influenced by her perspective, and potentially a need to present the group in a positive light.

Another limitation to this study is the use of measures. Due to the sparsity of literature and studies on this group, the examiner relied on approximations in conceptualizing this study. A number of measures used in this study have never been used in a study of Nigeria-Americans, and furthermore, the variables used in the study have never been organized in this manner. While this provides an avenue to detect new relationships not readily apparent from a literature review alone, it could limit the ability to generalize findings as it relates to existing theory and research. Future research may utilize qualitative methods to build on study findings to develop targeted insight into these findings, and what they mean for the population in a real-world setting.

Lastly while sample size was sufficient to conduct multiple regression analyses, it is important to note that the sample size fell short of the standards of a moderatedmediation analysis by nine data points. As such hypotheses five and six were tested in an exploratory manner. Although some argue that exploratory moderations and mediations are likely to detect accurate relationships (Serang et al., 2017) future research is warranted before making generalizable claims specific to those findings.

\section{Clinical Implications}

The findings of this study have far-reaching implications for mental health providers, government agencies, educators, researchers, methodologists, and policy- 
makers. It highlights the need to incorporate cultural considerations into research, in the early stages of study conceptualization. As results from this study show ways in which outcomes may differ based on the measure chosen to study a particular construct. Researchers and methodologists should understand the values and cultural framework their targeted population operates from, and use that to guide decision-making as it pertains to measure selection. Furthermore, historically researchers have grouped African-Americans and Nigerian-Americans into a singular group. However perceived discrimination's inability to serve as a predictor for this group indicates unique challenges, and as such it is also important to consider ways both groups may differ as opposed to assuming homogeneity based on race.

Mental health providers who work with Nigerian-American clientele may find it beneficial to consider cultural implications in their construction of well-being. Traditionally outcomes are conceptualized using the absence of affective symptoms indicative of a larger diagnostic concept, with heavy emphasis on personality (Mendelberg, 2018). Findings from this study suggests the importance of concepts related to connectivity with culture, community, and customs when working with NigerianAmericans. The significance of resilience as a multidimensional construct and that of the relational well-being scale suggests incorporating cultural elements may be an added dimension of wellness. As such, in identifying etiology of pathology clinicians may gain valuable insight by exploring a client's sense of belonging, and their ability to maintain cultural contact, practice customs, and participate in rituals and traditional rites of passage. Furthermore, clinicians should recognize that despite protective factors such as ethnic identity, and resilience, Nigerian-Americans may remain vulnerable to 
acculturative stress. As such, governmental agencies, policy-makers, and mental health providers should consider systemic constructs and barriers that may contribute to acculturative stress, and design policy and programs that facilitate integration and wellbeing that is also culturally appropriate. 


\section{REFERENCES}

Adédíran, B. (1985). Research on pre-Colonial western Yorùbáland: A note on sourceMaterials. Anthropos, 80(4/6), 545-554. Retrieved from http://www.jstor.org/stable/40461058.

Adetugbo, A. (1978). The development of English in Nigeria up-to 1914: A socio historical appraisal. Journal of the Historical Society of Nigeria. 9(2), 89-103. Retrieved from http://www.jstor.org/stable/41857063.

Alba, R., Raboteau, A. J., \& DeWind, J. (2009). Immigration and Religion in America. Comparative and Historical Perspectives. New York and London. New York University Press.

Aloba, O, Ajao, O., Alimi, T. \& Esan, O. (2016). Psychometric properties and correlates of the Beck Hopelessness Scale in family caregivers of Nigerian patients with psychiatric disorders in southwestern Nigeria. Journal of Neuroscience in Rural Practice, 7S18-S25. doi: 10.4103/0976-3147.196434.

Amadi, I. (2000). Society, production and distribution in precolonial southeastern Nigeria. Africa: Rivista Trimestrale Di Studi E Documentazione Dell'Istituto Italiano per L'Africa E L'Oriente, 55(3), 398-406. Retrieved from http://www.jstor.org/stable/40761463. 
Arizala, K. O. L. (2012). The effects of parental historical trauma and stressful events on youth outcomes in American Indian families. Dissertation Abstracts International, 73, 1281.

Attah, N. E. (2013). Contesting exclusion in a multi-ethnic state: Rethinking ethnic nationalism in Nigeria. Social Identities: Journal for the Study of Race, Nation and Culture 19(5), 607-620. doi:10.1080/13504630.2013.835515.

Ayokhai, F., Suleiman, M., \& Ngarka, T. (2013). Rethinking social change in Nigeria: Historicizing emirate and colonial rules in the Muri area of north-eastern Nigeria. Journal of the Historical Society of Nigeria, 22, 158-177. Retrieved from http://www.jstor.org/stable/24768921.

Azeez, N. (2012). Survey: Nigerians most educated in the U.S. BET. Retrieved from: http://www.bet.com/news/national/2012/03/20/survey-nigerians-most-educated in-the-u-s.html.

Bai, J. (2016). Development and validation of the Acculturative Stress Scale for Chinese college students in the United States (ASSCS). Psychological Assessment, 28,(4), 443-447. doi:10. 1037/pas0000198.

Balogun, O. M. (2011). No necessary tradeoff: Context, life course, and social networks in the identity formation of second-generation Nigerians in the U.S.A. Ethnicities, 11(4), 436-466.

Bas-Sarmieno, P., Saucedo-Moreno, M. J., Fernandez-Guitierrez, M., \& Poza-Mendez, M. (2017). Mental health in immigrants versus native population: A systematic review of the literature. Archives of Psychiatric Nursing, 31(1), 111-121. 
Batalova, J., \& Terrazas, A. (2013). The long view: The past, present, and future of U. S. immigration. In E. L. Grigorenko (Eds.), U.S. immigration and education: Cultural and policy issues across the lifespan (pp. 17-40). New York, NY, US: Springer Publishing Co.

Berry, J. W., Phinney, J. S., Sam, D.L., \& Veddeer, P. (2006). Immigrant youth: Acculturation, identity, and adaptation. Applied Psychology: An International Review, 55(3), 3030-332. doi:10.111/j.1464-0597.200600256.x.

Berry, J. W., Poortinga, Y. H., Segall, M. H., \& Dasen, P. R. (2002). Cross-cultural Psychology: Research and Application ( $2^{\text {nd }}$ ed.). New York, NY, US: Cambridge University Press.

Birman, D. (2006). Acculturation gap and family adjustment: Findings with Soviet Jewish refugees in the United States and implications for measurement. Journal of Cross Cultural psychology, 37(5), 568-589. doi: 10.1177/0022022106290479.

Bottrell, D. (2009). Understanding 'marginal' perspectives: Towards a social theory resilience. Qualitative Social Work: Research and Practice, 8(3), 321-339. doi: $10.1177 / 1473325009337840$.

Bourguignon, D., Seron, E., Yzerbvt, V., \& Herman, G. (2006). Perceived group and personal discrimination: Differential effects on personal self-esteem. European Journal of Social Psychology, 36(5), 773-789. doi:10.1002/ejsp.326.

Campbell-Sills, L., \& Stein, M. B. (2007). Psychometric analysis and refinement of the Connor Davidson Resilience Scale (CD-RISC): Validation of a 10-item measure of resilience. Journal of Traumatic Stress, 20, 1019-1028. 
Cardoso, J. B., \& Thompson, S. J. (2010). Common themes of resilience among Latino immigrant families: A systematic review of the literature. Families in Society, 91(3), 257-265. doi: 10.1606/1044-3894.4003.

Chakawa, A. Butler, R. C., \& Shapiro, S. K. (2015). Examining the psychometric validity of the Multigroup Ethnic Identity Measure- Revised (MEIM-R) in a community sample of African American European American adults. Cultural Diversity and Ethnic Minority Psychology, 21(4), 643-648. doi:10.1037/cdp0000025.

Connor, K. M., \& Davidson, J. R. (2003). Development of a new resilience scale: The Connor-Davidson Resilience Scale (CD-RISC). Depression and Anxiety, 18(2), 76-82.

Constantine, M. G., Okazaki, S., \& Utsey, S. O. (2004). Self-concealment, social selfefficacy, acculturative stress, and depression in African, Asian, and Latin American international college students. American Journal of Orthopsychiatry, 74(3), 230-241. doi:10.1037/0002-9432.74.3.230.

Cosco, T. D., Kaushal, A., Richards, M., Kuh, D. \& Stafford, M. (2016). Resilience measurement in later life: A systematic review and psychometric analysis. Health and Quality of Life Outcomes, 14(16). 1-6. doi: 10.1186/s12955-016-0418-6.

Daramola, O., \& Scisney-Matlock, M. (2014). Migration and cognitive representations of hypertensions in African immigrants women. Western Journal of Nursing Research, 36(2), 209-227. doi:10.1177/0193945913504501.

Deenesh, S. (2007). Unsuitable suitors: Anti-miscegenation laws, naturalization laws, and the construction of Asian identities. Law \& Society Review, 41(3), 587-618. Retrieved from http://www.jstor.org/stable/4623396. 
Diaz, T., \& Bui, N. H. (2016). Subjective well-being in Mexican and Mexican-American women: The role of acculturation ethnic identity, gender roles, and perceived social support. Journal of Happiness Studies, doi:10.1007/s10902-016-9741-1.

Duffy, R. D., \& Klingaman, E. A. (2009). Ethnic identity and career development among first year college students. Journal of Career Assessment, 17(3), 286-297.

Eisenstadt, S. N. (1953). Analysis of patterns of immigration and absorption of immigrants. Population Studies, 7(2), 167-180. http://doi.org/10.2307/2172030

Essien, D. O.. (1995). The pre-colonial economy of Akwa Ibom. Transafrican Journal of History, 24, 186-194. Retrieved from http://www.jstor.org/stable/24328663.

Ette, E. U. (2012). Nigerian Immigrants in the United States. Race, Identity, and Acculturation. Lanham Maryland: Lexington Books.

Field, A. (2009). Discovering Statistics Using SPSS: (and sex and drugs and rock ' $n$ ' roll). Los Angeles [i.e. Thousand Oaks, Calif.]: SAGE Publications.

Fonagy, P., Steele, M. Steele, H., Higgitt, A., \& Target, M. (1994). The Emanuel Miller Memorial lecture 1992: The theory and practice of resilience. Journal of Child Psychology \& Psychiatry, 37(8), 231-257. doi:10.1111/j.1469 7610.1994.tb01160.x.

Friborg, O., Hjemdal, O., Rosenvinge, J. H., \& Martinussen, M. (2003). A new rating scale for adult resilience: What are the central protective resources behind healthy adjustment? International Journal of Methods in Psychiatric Research, 12(2), 65 76. doi:10.1002/mpr.143. 
Gonzales, K. L., Noonan, C., Goins, R. T., Henderson, W. G., Beals, J., Manson, S. M., \& ... Roubideaux, Y. (2016). Assessing the Everyday Discrimination Scale among American Indians and Alaska Natives: Psychological Assessment, 28(1), 51-58. doi:10.1037/a0039337.

Grambs, J. D. (1983). One nation indivisible? Ethnicity in American history and education. Childhood Education, 60(2), 77-83.

Herrington, H. M., Smith, T. B., Feinauer, E., \& Griner, D. (2016). Reliability generalization of the Multigroup Ethnic Identity Measure-Revised (MEIM-R). Journal of Counseling Psychology, 63(5), 586- 593. doi:10.1037cou0000148.

Hjemdal, O., Roazzi, A., Dias, M. B. B., \& Friborg, O. (2015). The cross-cultural validity of the Resilience Scale for Adults: A comparison between Norway and Brazil. BMC Psychology, 3(18), 1-9. https//doi.org/10.1186/s40359-015-0076-1.

Hjemdal, O., Friborg, O., Braun, S., Kempenaers, C., Linkowski, P., \& Fossion, P. (2011). The Resilience Scale for Adults: Construct validity and measurement in a Belgian sample. International Journal of Testing, 11(1), 53-70. doi:10.1080/15305058.2010.508570.

Homma, Y., Zumbo, B. D., Saewyc, E. M., \& Wong, S. T. (2014). Psychometric evaluation of the six-item version of the Multigroup Ethnic Identity Measure with East Asian adolescents in Canada. Identity, 14(1), 1-18. doi:10.1080/15283488.2013.858227.

Horton, J. (1998). [The emergence of racial modernity and the rise of the White north, 1790-1840]: Comment. Journal of the Early Republic, 18(2), 222-225. doi:10.2307/3124890. 
Hooper, L. M., Wallace, S. A., Doehler, K., \& Dantzler, J. (2012). Parentification, ethnic identity, and psychological health in Black and White American college students: Implications of family-of-origin and cultural factors. Journal of Comparative Family Studies. 43(6), 811-835.

Hopwood, C. J. (2007). Moderation and mediation in structural equation modeling: Applications for early intervention research. Journal of Early Intervention, 29(3), 262-272. doi:10.1177/105381510702900305.

Hu, L., Bentler, P. M. (1999). Cutoff criteria for fit indexes in covariance structure analysis: Conventional criteria versus new alternatives, Structural Equation Modeling: A Multidisciplinary Journal, 6(1), 1-55. doi: $10.1080 / 10705519909540118$.

Ibrahim, J. (1991). Religion and political turbulence in Nigeria. Journal of Modern AfricanStudies, 29(1), 115-136. Retrieved from http://www.jstor.org/stable/160995.

Imbua, D. (2013). Slavery and slave trade remembered: A study of the slave history museum in Calabar, Nigeria. Journal of the Historical Society of Nigeria, 22, 112 136. Retrieved from http://www.jstor.org/stable/24768919.

Iweriebor, E. G. (1982). State systems in pre-colonial colonial and post-colonial Nigeria: An overview. Africa: Rivista Trimestrale Di Studi E Documentazione Dell'istituto Italian Per L'africa E L'oriente, 37(4), 507-513. Retrieved from http://www.jstor.org/stable/40759619. 
Jakobsen, J. C., Gluud, C., Wetterslev, J., \& Winkel P. (2017). When and how should multiple imputation be used for handling missing data in randomised clinical trials - a practical guide with flowcharts. BMC Medical Research Methodology, 17(162). https://doi.org/10.1186/s12874-017-0442-1.

Jibeen, T., \& Khalid, R. (2010). Development and preliminary validation of multidimensional acculturative stress scale for Pakistani immigrants in Toronto Canada. International Journal of Intercultural Relations, 34(3), 233-243. doi: 10.1016.

Kavass, I. I. (1962). Migrant Assimilation. The Australian Quarterly, 34(2), 54-66. http://doi.org/10.2307/20633786.

Kenny, D. A. (2011). Terminology and basics of SEM. Retrieved from http://www.davidakenny.net/cm/basics.htm.

Kim, I. (2016). Beyond trauma: Post-resettlement factors and mental health outcomes among Latino and Asian refugees in the United States. Journal of Immigrant and Minority Health, 18(4), 740-748.doi:10.1007/s10903-015-0251-8.

King, A. G. (1983). A brief for a tax-based U.S. immigration policy. Population Research and Policy Review, 2(1), 1-19.

Kline, R. B. (2011). Principles and Practice of Structural Equation Modeling, $3^{\text {rd }}$ edition, New York, Guilford Press.

Kpone-Tonwe, S. (2001). Leadership training in precolonial Nigeria: The Yaa tradition of Ogoni. The International Journal of African Historical Studies, 34(2), 385-403. 
Lamp, F. J. (2011). Ancient terracotta figures from northern Nigeria. Yale University Art Gallery Bulletin, 48-57. Retrieved from http://www.jstor.org/stable/41421509.

Lang, W., \& Mercier, L. (1984). Getting It down right: Oral history's reliability in local history research. The Oral History Review, 12, 81-99. Retrieved from http://www.jstor.org/stable/3675284.

Lau, A. S., McCabe, K. M., Yeh, M., Garland, A. F., Wood, P. A., \& Hough, R. L. (2005). The acculturation gap distress hypothesis among high-risk Mexican American families. Journal of Family Psychology, 19(3), 367-375. doi: 10.1037/0893-3200.19.3.367.

Lenshie, N. (2014). Ties that bind and differences that divide: Exploring the resurgence of ethno-cultural identity in Nigeria. Africa Development/ Afrique Et Developpement, 39(2), 153-212. Retrieved from http://www.jstor.org/stable/afrdevafrdev.39.2.153.

Liu, D. Y., Fairweather-Schmidt, A. K., Burns, R. A., \& Roberts, R. M. (2015). The Connor-Davidson Resilience Scale: Establishing invariance between gender across the lifespan in a large community based study. Journal of Psychopathology \& Behavioral Assessment, 37(2), 340-348. Doi:10.1007/s10862-014-9452-z.

Liu, Y., Chen, X., Li, S., Yu, B., Wang, Y., \& Yan, H. (2016). Path analysis of acculturative stress components and their relationship with depression among international students in China. Journal of the International Society for the Investigation of Stress, 32(5), 524-532. doi:10.1002/smi.2658.

Lovejoy, P. (1974). Interregional Monetary Flows in the precolonial trade of Nigeria. 
The Journal of African History, 15(4), 563-585. Retrieved from

http://www.jstor.org/stable/180991.

Lopez, G., \& Bialik, K. (2017). Key findings about U.S. immigrants. Retrieved from: http://www.pewresearch.org/fact-tank/2017/05/03/key-findings-about-u-s immigrants/

Makanjuola, V. A., Onyeama, M., Nuhu, F. T., Kola, L., \& Gureje, O. (2014). Validation of short screening tools for common mental disorders in Nigerian general practices. General Hospital Psychiarty, 36(3), 325-329. doi:10.1016/j.genhosppsych.2013.12.010.

McCubbin, H. I. (1979). Integrating coping behavior in family stress theory. Journal of Marriage and the Family, 41(2), 237-244. doi:10.2307/351693.

McCubbin, L. D., McCubbin, H. I., Zhang, W., Kehl, L., \& Strom, I. (2013). Relational well-being: An indigenous perspective and measure. Family Relations, 62(2), 354-365. doi:10.1111/fare.12007.

McCubbin, H. I., \& Patterson, J. M. (1983). The family stress process: The double ABCX model of adjustment and adaptation. Marriage \& Family Review, 6(1-2), 7-37. doi:10.1300/J002v06n01_02.

McDonald, R. P., \& Ho. M. R. (2002). Principles and practice in reporting structural equation analyses. Psychological Methods, 7(1), 64-82. doi: 10.1037/1082 989X.7.1.64.

Migration Policy Institute. (2016). Frequently requested statistics on immigrants and 
immigration to the United States. Retreived from:

http://www.migrationpolicy.org/article/frequently-requested-statisticsimmigrants-and-immigration-united-states.

Migration Policy Institute. (2015). The Nigerian diaspora in the United States. Retrieved from: www.migrationpolicy.org/sites/degault/files/publications/RAD-Nigeria.pd

Migration Policy Institute. (2012). Diverse streams: African migration to the United States. Retrieved from: http://www.migrationpolicy.org/research/CBI-african migration-united-states.

Moomal, H., Jackson, P., Stein, D. J., Herman, A., Myer, L., Seedat, D., Williams, D. R. (2009). Perceived discrimination and mental health disorders: The South African stress and health study. South African Medical Journal, 99(5), 383-389. Retrieved from pubmedcentralcanada.ca/pmcc/articles/PMC3191948/pdf/nihms327606.pdf.

National Institute for Health, (2010). Health disparities. Retrieved from: https://report.nih.gov/nihfactsheets/Pdfs/HealthDisparities(NIMHD).pdf Naturalization Act of 1790, 1 U.S.C. § section 1 1-755.

National Vital Statistics Report, (2016). Deaths: Final data for 2014. Retrieved from: https://www.cdc.gov/nchs/data/nvsr/nvsr65/nvsr65_04.pdf.

Nigerian History. (n.d.). 2016, Retrieved from: http://thecommonwealth.org/our-member countries/nigeria/history

Nguyen, T. T., Bellehumeur, C., \& Malette, J. (2015). God images and resilience: A study of Vietnamese immigrants. Journal Of Psychology And Theology, 43(4), 
271-282.

Ochonu, M. (2009). Critical convergence: The great depression and the meshing of Nigerian and British anti-colonial polemic. Canadian Journal of African Studies/ Revue Canadienne Des Etudes Africaines, 43(2), 245-281. http://www.jstor.org/stable/20743818.

Okonofua, B. A. (2013). "I am blacker than you": Theorizinng conflict between African immigrants and African Americans in the United States. Sage Open, 1-14. doi: $10.1177 / 2158244013499162$.

Okpeh, O. (2008). Patterns and dynamics of inter-group relations in Nigeria, 1800-1900 AD. Journal of the Historical Society of Nigeria, 17, 123-137. Retrieved from http://www.jstor.org/stable/41857151.

Oloyede, I. (2017, January 25). Islam in Nigeria: A century of National Islamic Societies Address presented at International Conference of Islam in Nigeria in University of Ilorin, November 24, 2014.

Ong, A. D., Bergeman, C. S., \& Boker, S. M. (2009). Resilience comes of age: Defining features in later adulthood. Journal of Personality, 77(6), 1777-1804. doi:10.111/j.14676494.2009.00600.x.

Passel, J. S. (2011). Demography of immigrant youth: Past, present and future. The Future of Children, 21(1). 19-41. doi:10.1353/foc.2011.0001.

Passel, J. S., \& Cohn, D. (2017). Immigration projected to drive growth in U.S. working age population through at least 2035. Retrieved from: 
http://www.pewresearch.org/facttank/2017/03/08/immigration-projected-to-drive growth-in-u-s-working-age-population through-at-least-2035/.

Passel, J. S., \& Fix, M. (1994). U. S. Immigration in a global context: Past, present, and future. Indiana Journal of Global Legal Studies, 2, 5-19.

Pew Research Center. (2008). U.S. population projections: 2005-2050. Retreived from: http://www.pewhispanic.org/2008/02/11/us-population-projections-2005-2050/.

Pew Research Center. (2015). African immigrant population in U.S. steadily climbs. Retrieved from: http://www.pewresearch.org/fact-tank/2015/11/02/african immigrant-population-in-u-s-steadily-climbs/.

Phinney, J. S., Cantu, C. L. \& Kurtz, D. A. (1997). Ethnic and American identity as predictors of self-esteem among African-American, Latino, and White adolescents. Journal of Youth and adolescence 26(2), 165-185. doi:10.1023/A:1024500514834.

Phinney, J. S., \& Ong, A. D. (2007). Conceptualization and measurement of ethnic identity: Current status and future directions. Journal of Counseling Psychology, 54(3), 271-281. doi:10.1037/0022-0167.54.3.271.

Preacher, K. J., \& Hayes, A. F. (2004). SPSS and SAS procedures for estimating indirect effects in simple mediation models. Behavior Research Methods, Instruments, \& Computers, 36(4), 717-731. Retrieved from https://kuscholarworks.ku.edu/bistream/handle/1808/1491/preacher_hayes_2004 pdf?sequence $=1 \&$ is Allowed $=\mathrm{y}$ 
Reynolds, R. (2002). An African brain drain: Igbo decisions to immigrate to the US. Review of African Political Economy. 29(92), 273-284. Retrieved from http://www.jstor.org/stable/4006815.

Rhea, D. J., \& Thatcher, W. G. (2013). Ethnicity, ethnic identity, self-esteem, and at-risk eating disordered behavior differences of urban adolescent females. The Journal of Treatment \& Prevention, 21(3), 223-237.

Rodgriguez, J. J. (2007). Acculturative factors and mental health among Latinos: A meta analytic review. Dissertation Abstracts International. 67. 7389.

Romero, A. J., Edwards, L. M., Fryberg, S.A., Orduna, M. (2014). Resilience to discrimination stress across ethnic identity stages of development. Journal of Applied Social Psychology, 4. 1-11 https://doi.org/10.1111/jasp.12192

Ross, B. M., \& Millsom, C. (1970). Repeated memory of oral prose in Ghana and New York. International Journal Of Psychology, 5(3), 173-181. doi:10.1080/00207597008246667.

Rubin, E.. (1966). The demography of immigration to the United States. The Annals of the $=$ American Academy of Political and Social Science, 367, 15-22. Retrieved from http://www.jstor.org/stable/1034839.

Ryan, A. M., Gee, G. C., \& Laflamme, D. F. (2006). The association between self reported discrimination, physical health and blood pressure: Findings from African Americans, Black Immigrants, and Latino immigrants in New Hampshire. Journal of Health Care for the Poor and Underserved. 17(2), 116-132. doi:10.1353/hpu.2006.0079. 
Sandhu, D. S., \& Asrabadi, B. R. (1994). Development of an acculturative stress scale for international students: Preliminary findings. Psychological Reports, 75(1, Pt 2), 435-448. doi:10.2466/pr0.1994.75.1.435.

Schachter, A. (2016). From 'different' to 'similar.' An experimental approach to understanding assimilation. American Sociological Review, 81(5), 981-1013. doi:10.1177/0003122416659248.

Schwartz, S. J., \& Zamboanag, B. L. (2008). Testing Berry’s model of acculturation: A confirmatory latent class approach. Cultural Diversity and Ethnic Minority Psychology, 14(4), 275-285. doi:10.1037/a0012818.

Serang, S., Jacobucci, R., Brimhall, K. C., \& Grimm, K. J. (2017). Exploratory mediation analysis via regularization. Structural Equation Modeling : A Multidisciplinary Journal, 24(5), 733-744. https://doi.org/10.1080/10705511.2017.1311775.

Smith, N. (2015). It isn't just Asian immigrants who thrive in the U.S. Bloomberg View. Retrieved from: https://www.bloomberg.com/view/articles/2015-10-13/it-isn-tjust-asian-immigrants-who-excel-in-the-u-s-

Smith, T. B. \& Silva, L. (2011). Ethnic identity and personal well-being of people of color: A meta-analysis. Journal of Counseling Psychology, 58, 42-60.

Southwick, S. M., Bonanno, G. A., Masten, A. S., Panter-Brick, C., \& Yehuda, R. (2014). Resilience definitions, theory, and challenges: Interdisciplinary perspectives. European Journal of Psychotraumatology 5, 25338 http://dx.doi.org/10.3402/ejp.v5.25338.

Stevens, J. (2007). Intermediate Statistics: A modern approach: New York: Lawrence Erlbaum Associates. 
Stronge, S., Sengupta, N. K., Barlow, F. K., Osborne, D., Houkamau, C. A., \& Sibley, C. G. (2016). Perceived discrimination predicts increased support for political rights and life satisfaction mediated by ethnic identity: A longitudinal analysis. Cultural Identity \& Ethnic Minority Psychology, 22(3), 359-368. doi:10.1037/cdp0000074.

Totten, R.. (2008). National Security and U.S. Immigration Policy, 1776-1790. The Journal of Interdisciplinary History, 39(1), 37-64. Retrieved from http://www.jstor.org/stable/20143762.

Topp, C. W., Ostergaard, S. D., Sondergaard, S., \& Bech, P. (2015). The WHO-5 Well Being Index: A systematic review of the literature. Psychotherapy and Psychosomatics, 84, 167-176.

Tran, A. T., Lee, R. M., \& Burgess, D. J. (2010). Perceived discrimination and substance abuse in Hispanic/Latino, African-born Black, and southeast Asian immigrants. Cultural Diversity \& Ethnic Minority Psychology, 16(2), 226-236. doi:10.1037/a0016344.

United States Embassy in Nigeria. (2012). Economic Studies. Retrieved from: http://nigeria.usembassy.gov.

van Breda, A. D. (2001). Resilience theory: A literature review. Retrieved from www.vanbreda.org/adrian/resilience/resilience_theory_review. pdf.

Walters, J. (2015). Snowball sampling: A cautionary tale involving a study of older drug users. International Journal of Social Research Methodology: Theory \& Practice, 18(4), 367- 380. doi:10.1080/13645579.2014.953316.

Windle, G. (2011). What is resilience? A review and concept analysis. Reviews in Clinical Gerontology, 21(2). 152-169. doi:10.1017/S0959259810000420. 
Williams, D. R., Gonzalez, H. M., Williams, S., Mohammed, S. A., Moomal, H., \& Stein, D. J. (2008). Perceived discrimination, race and health in South Africa, Social Science \& Medicine, 67(3), 441-452. doi:10.1016/j.socscimed.2008.03.021.

Williams, D. R, Yu, Y., Jackson, J.S., \& Anderson, N.B. racial differences in physical and mental health: Socioeconomic status, stress, and discrimination. Journal of Health Psychology, 2(3), 335-351.

Werner, E. (1993). Risk, resilience, and recovery: Perspectives from the Kauai longitudinal study. Development \& psychopathology, 5, 503-515.

Werner, E., \& Brendtro, L. (2012). Risk, resilience, and recovery. Reclaiming Children \& Youth, 21(1), 18-22.

Wong, Y. J., Wang, K. T., \& Maffini, C. S. (2014). Asian international students' mental health-related outcomes: A Person x Context cultural framework. The Counseling Psychologist, 42(2), 278-305. doi:10.1177?0011000013482592.

Wu, W., \& Jia, F. (2013). A new procedure to test mediation with missing data through nonparametric bootstrapping and multiple imputation. Multivariate Behavioral Research, 48(5), 663-691. doi:10.1080/00273171.2013.816235

Yakhnich, L. (2008). Immigration as a multiple-stressor situation: Stress and coping among immigrants from the former Soviet Union in Israel. International Journal of Stress Management, 15(3), 252-268.

Zvolensky, M. J., Jardin, C., Garey, L. Robles, Z., \& Sharp, C. (2016). Acculturative stress and experiential avoidance: Relations to depression, suicide, and anxiety symptoms among minority college students. Cognitive Behaviour Therapy, 45(6), 501-517. doi:10.1080/16506073.2016.1205658. 
Table 1

Indicator of Each Last Matching Case as Primary

\begin{tabular}{ccccc} 
& Frequency & Percent & Valid Percent & Cumulative Percent \\
\hline Valid Duplicate Case & 3 & 2.0 & 2.0 & 2.0 \\
Primary Case & 150 & 98.0 & 98.0 & 100.0 \\
Total & 153 & 100.0 & 100.0 & \\
\hline
\end{tabular}

Note. Summary of duplicate data. 
Table 2

Correlations for Acculturative Stress, Resilience, Ethnic Identity, and Perceived Discrimination

Variable

2

3

4

5

1. ASSIS

2. RSA

3. CD-RISC

4. MEIM

$-.19 *$

$-.05$

5. EEDS

.15

$.57 * *$

$.37 * *$

$.22 * *$

$-.28 * *$

.2

$-.02$

$-$

Note. ASSIS $=$ Acculturative Stress, $\mathrm{RSA}=$ Resilience Scale for Adults, CD-RISC=

Connor Davidson Resilience Scale, MEIM= Ethnic Identity, EEDS= Perceived

Discrimination $* * \mathrm{p}<.01, * \mathrm{p}<.05$ 
Table 3

Psychological Well-being, Relational Well-being, and Psychological Distress as Dependent Variables

\begin{tabular}{|c|c|c|c|c|c|c|c|c|c|c|}
\hline \multirow[t]{2}{*}{ IV } & \multicolumn{4}{|c|}{ Relational Well-being } & \multicolumn{3}{|c|}{ Psychological Well-being } & \multicolumn{3}{|c|}{ Psychological Distress_ } \\
\hline & $B$ & $S E$ & $\begin{array}{lll}\beta & \mathrm{R}^{2} & \Delta \mathrm{R}^{2}\end{array}$ & $\mathrm{~F}$ & $\begin{array}{llll}B & S E & \beta & \mathrm{R}^{2}\end{array}$ & $\Delta \mathrm{R}^{2}$ & $\mathrm{~F}$ & $\begin{array}{llll}B & S E & \beta & \mathrm{R}^{2}\end{array}$ & $\Delta \mathrm{R}^{2}$ & $\bar{F}$ \\
\hline Model 1 & & & .05 .03 & $3.49 * *$ & .04 & .03 & $3.11 * *$ & .07 & .06 & $5.40 * *$ \\
\hline ASSIS & -.15 & .10 & -.09 & & $\begin{array}{lll}-.19 & .10 & -.19 * *\end{array}$ & & & $.23 .10 .23 * *$ & & \\
\hline EEDS & -.09 & .10 & -.15 & & $\begin{array}{lll}-.01 & .10 & -.01\end{array}$ & & & .05 .10.05 & & \\
\hline Model 2 & & & $.38 \quad .37$ & $30.54 * *$ & .52 & .51 & $52.19 * *$ & .26 & .24 & $17.10^{* *}$ \\
\hline RSA & .37 & .07 & $.37 * *$ & & $.64 \quad .06 \quad .64 * *$ & & & $-.49 .08-.49 * *$ & & \\
\hline CD-RISC & .32 & .07 & $.32 * *$ & & $.18 \quad .06 \quad .18 * *$ & & & $-.04 .08-.04$ & & \\
\hline MEIM & .14 & .07 & $.14 * *$ & & $\begin{array}{lll}-.04 & .06 & -.04\end{array}$ & & & $-.02 .07 \quad .02$ & & \\
\hline
\end{tabular}

Note. ASSIS= Acculturative Stress, EEDS= Expanded Everyday Discrimination Scale, RSA= Resilience Scale for Adults,

CD-RISC $=$ Connor Davidson Resilience Scale, MEIM $=$ Multi-ethnic Identity Measure. $* * p<.05$ 
Figure 1.1: The Double ABCX model.

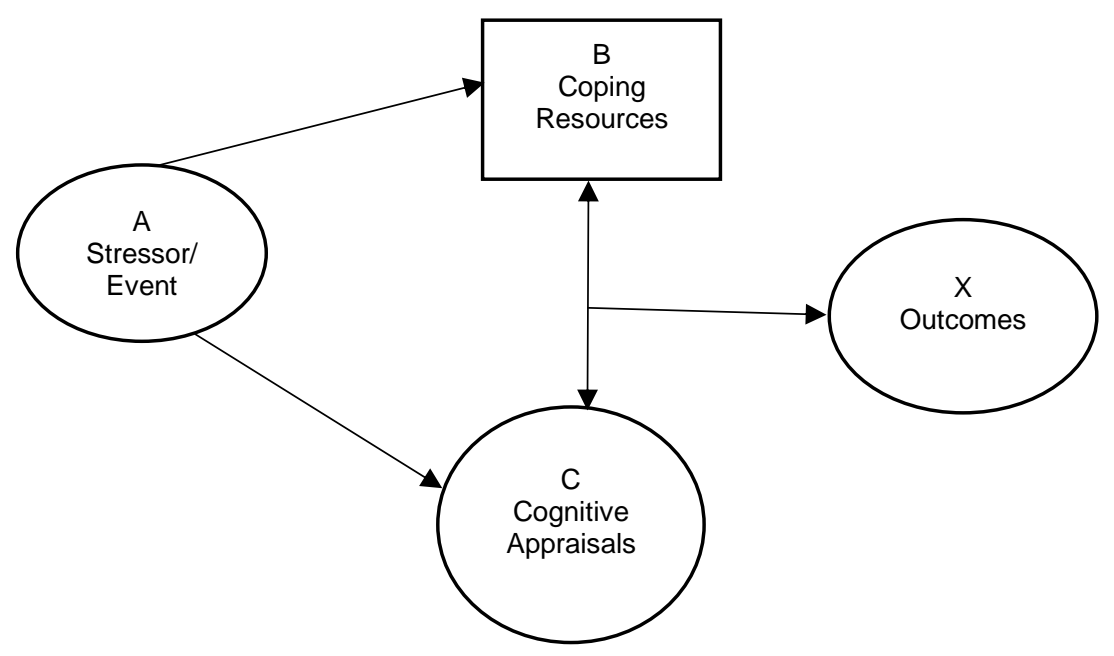


Figure 1.2 The Double ABCX model with study variables.

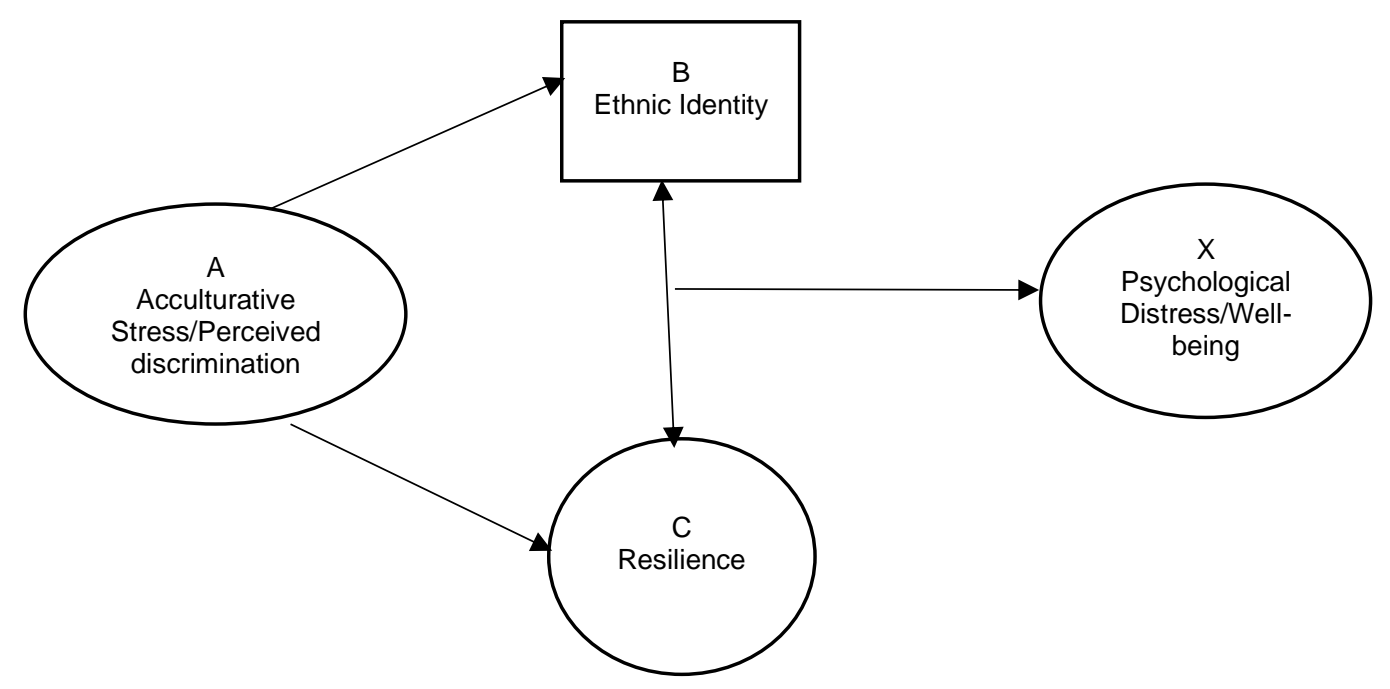


Figure 2.1 Exploratory moderated-mediation analysis.

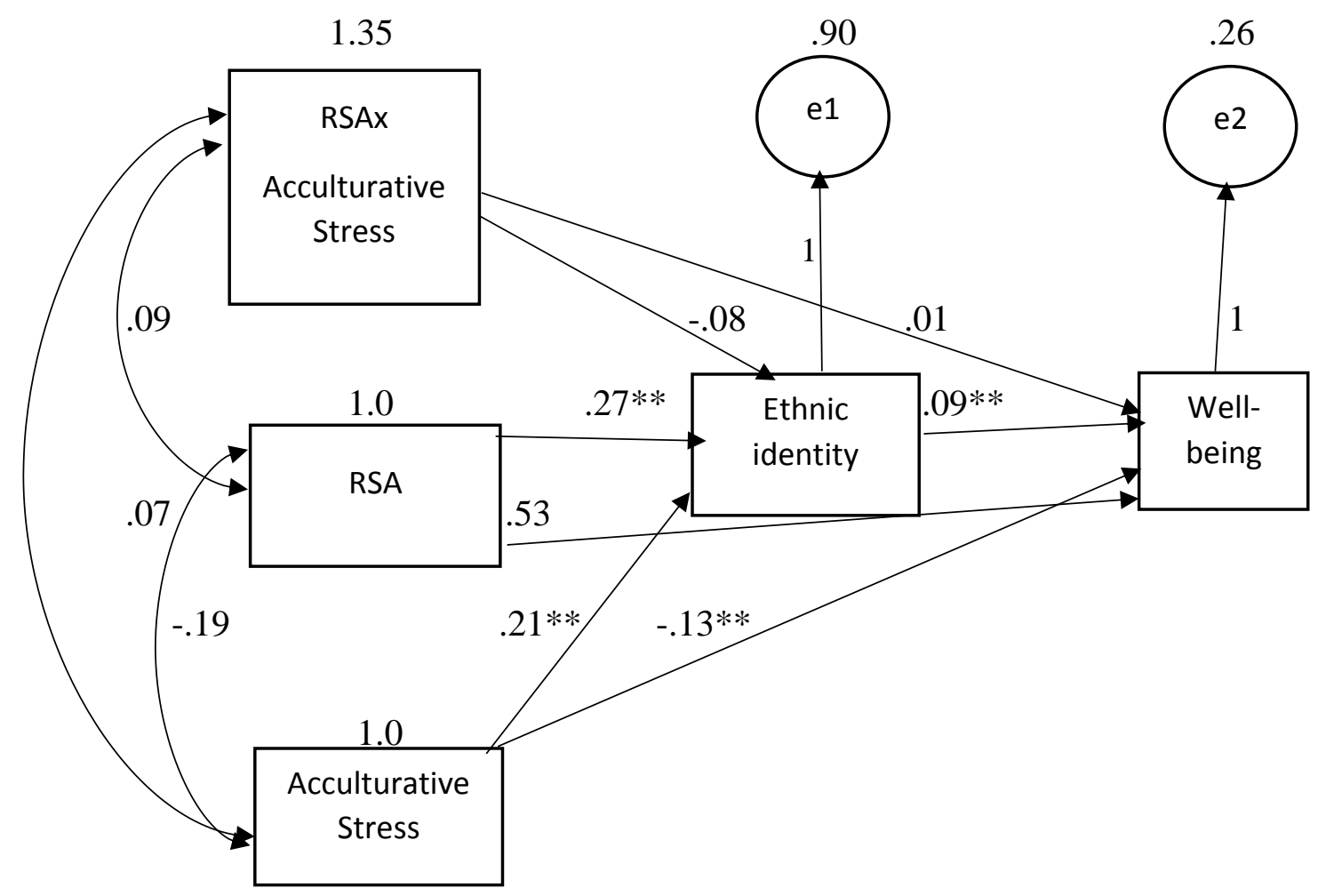

Note. ${ }^{* *} \mathrm{p}<.05$ 


\section{CURRICULUM VITA}

K. Chinwe Idigo

201-745-1399

Chinwe.idigo@louisville.edu

\section{Education}

Doctor of Philosophy, Counseling Psychology, 2020

University of Louisville, Louisville, KY

Master of Science, Counseling Psychology, 2008

Loyola University in Maryland, Baltimore, MD

Bachelor of Arts, Sociology, 2006

Temple University, Philadelphia, PA

\section{Clinical Training}

\section{Bergen County Division of Family Guidance}

- Conduct clinical intakes using psychological testing for juvenile diversion programs.

- Develop and implement group therapy for adolescent girls at juvenile detention center.

- Provide juvenile sex-offender treatment to court mandated referrals.

- Implement psycho-education programs to address juvenile delinquent behaviors identified by local police.

- Work with adolescent and families to treat complex trauma.

\section{Rutgers University Behavioral/Correctional Healthcare}

Newark, New Jersey

Psychology Intern

July 2018- June 2019

Acute Partial Hospitalization 
- Provided group therapy (anger management, dual diagnosis, finding balance, \& Women's group) to acute adult population with and without forensic histories in support of transition into mainstream society.

- Developed and administered unit-based trainings to enhance intervention, and care.

- Worked with short and long-term therapy cases with clients impacted by sexual and physical violence, substance abuse bipolar, and psychotic disorders.

- Facilitated the use of coping skills to gain insight into emotional experiences in order to increase medication adherence, and manage symptoms.

- Conducted psychological evaluation to facilitate diagnostic clarification, and rule out cognitive deficits.

- Attended weekly case conference meetings and consulted with interdisciplinary teams including psychiatrists, social workers, and case managers.

Adult Outpatient Services

July 2018 - June 2019

- Maintained a caseload of 6 individual therapy cases treating chronic trauma, sexual abuse, depression, and anxiety.

- Conducted psychological testing to rule out traumatic brain injuries, and to clarify diagnosis.

- Attended bi-weekly interdisciplinary team meetings, and consulted with psychiatrists, nursing staff, social workers, and case managers.

- Conducted clinical intakes with incoming clients to determine appropriate level of care.

Student Wellness Program

September 2018 - June 2019

- Conduct individual psychotherapy with medical residents and dental students

- Conceptualize and treat clients from a psychodynamic perspective

- Read articles on psychodynamic theory, and discussed complex theoretical concepts

- Conduct psychological evaluation to determine testing needs for students.

University Hospital Crisis Child Consultation Liaison $\quad$ February 2019 - May 2019

- Assessed clients experiencing acute psychological symptoms to determine risk level.

- Referred clients to appropriate level of care, following stabilization.

- Conducted intakes to determine etiology of presenting symptoms in an acute setting.

- Worked on interdisciplinary team with psychiatrists, nursing staff, and screeners.

- Consulted with family members of client to obtain additional information to inform clinical decision-making.

- Provided family members with safety measures, and instructions for continuity of care. 


\section{Jamesburg Juvenile Justice Center- New Jersey Training School for Boys}

September 2018- January 2019

- Administered psychological assessments for diagnostic clarification for complex clinical cases.

- Provided individual therapy to facilitate transition into mainstream society and/or step-down programming.

- Conducted mental status exams, and brief clinical interventions to juveniles on special needs roster.

- Taught effective coping skills to manage PTSD symptoms.

- Reviewed clinical records, and integrated information from collateral resources into psychological reports.

- Evaluated appropriate residential setting within the facility based on psychological health, and risk level.

- Provided crisis intervention to clients presenting with acute symptoms.

- Consulted with family members to facilitate communication to reduce client stress, and improve treatment prognosis.

- Conducted program evaluations in forensic settings to determine fit for treatment environment.

\section{Associates in Counseling \& Psychotherapy,}

\section{New Albany, Indiana}

Assessment Therapist

- Assessed adolescents for the Indiana department of juvenile probation to determine cognitive, behavioral and emotional functioning.

- Conducted psychological evaluations to determine intellectual and emotional functioning of referrals from Indiana's Department of Child Services.

- Administered psychological assessment to determine diagnostic clarificationCommon diagnoses include Mood and Trauma-based disorders, Oppositional Defiant Disorder, Conduct Disorders.

- Wrote comprehensive psychological reports which included treatment recommendations for a number of providers.

- Administered clinical intakes to assess medical necessity for testing.

- Provided feedback to clients on report findings, including parenting recommendations for parents of at-risk adolescents.

\section{Providence House for Children}

\section{Georgetown, Indiana}

Psychology practicum

- Conducted individual, family, couples and group therapies for families involved with Indiana Department of Child Services due to severe abuse/neglect. 
- Provided individual and family therapy to families with sexually deviant adolescents in the household.

- Administered psycho-education, and skill building for adolescents and their families.

- Trained parents of delinquent youth on boundary setting, and parenting skills to remediate pathological behaviors.

- Attended case meetings to make recommendations for family reunification to the family court system.

- Provided parenting classes to parents involved with DCS due to a variety of challenges including substance abuse, domestic violence, and neglect.

- Conducted psychological evaluations, and assessments as needed.

\section{Kentucky Correctional Institution for Women}

\section{Pee Wee Valley, Kentucky}

Psychology practicum

August 2016- May 2017

- Conducted risk assessments to determine level of security required within the facility.

- Evaluated inmates to determine appropriate fit for various programs.

- Provided crisis interventions to inmates including grief counseling, acute trauma intervention, anxiety management, and mental status exams

- Assessed complex clinical cases with the use of psychological batteries to measure cognitive and emotional functioning, as well as malingering.

- Designed and implemented groups to serve high risk inmates, and reduce incidents of violent, self-harm and rule-breaking behaviors.

\section{University of Louisville, College Counseling Center,}

\section{Louisville, KY}

Supplemental practicum training

November 2015- April 2016

- Provided individual psychotherapy to traditional and non-traditional college aged students

- Managed a weekly caseload of 4-5 individual therapy clients,

- Attended didactic trainings including suicide response and use of assessments.

- Conducted outreach on college campus to improve well-being of campus community members.

- Attend weekly case conferences and present complex clinical cases to treatment team.

\section{Cardinal Success Program @NIA,}

\section{Louisville, KY}

Practicum training

August 2015- June 2016

- Provided psychological services to primarily low-income racial/ethnic minority residents in the West Louisville area. 
- Managed a weekly caseload of approximately 5 individual therapy clients, one family and one couple.

- Provided psycho-educational groups covering topics including stressmanagement, de-stigmatizing mental health and self-care.

- Provided outreach services to promote clinic to stakeholders including parole officers, community resource centers and religious leaders.

- Provided psychological assessments for Vocational rehabilitation, Kentucky Recovery Resource Center, Jefferson County Public Schools Adult Learning Center and court mandated mental health evaluations.

- Attended weekly case conference, and presented cases to clinical team.

University of Louisville, Group therapy course,

\title{
Louisville, KY
}

Group facilitator

February 2015- May 2015

Led weekly stress-management group designed to teach masters and doctoral level students self-awareness and group interpersonal processes.

\section{Bellarmine University, Counseling Center,}

\section{Louisville, KY}

Practicum training

August 2014- July 2015

- Provide individual psychotherapy services to students ages 18 to 28 .

- Provided outreach services to various organizations on campus including stress management, college transition, and diversity.

- Conducted certified peer educators training to student organization.

- Attended weekly case conferences and weekly individual supervision.

\section{University of Maryland, Department of Psychiatry, School Mental Health Program, Baltimore, MD \\ Psychology Externship \\ September 2007-May 2008}

- Provided individual psychotherapy to students between the ages of 6-15,

- Consulted with school officials to implement reinforcement based behavioral modification techniques. Led anger-management group with $5^{\text {th }}$ grade students. Implemented psycho-education program on early prevention of tobacco use. Weekly on-site supervision and bi-weekly supervision through the psychology department at Loyola University in Maryland

Supervisor: Jennifer Pitchford M.S. LCPC, James Finkelstein, PsyD

\section{Academic/Clinical Work Experience}

\author{
Associates in Counseling \& Psychotherapy, \\ New Albany, Indiana \\ Assessment Therapist
}

May 2016- May 2018 
Provided psychological evaluations in support of Indiana's Department of Child's Services (DCS) child placement and family reunification services and juvenile probation. Also provided clinical assessments and substance abuse assessments, including treatment recommendations. Worked with pain management physician to evaluate mental health status of recipients of a pain pump procedure.

Supervisor: Jessica Huett, PsyD

\section{University of Louisville, College of Education and Human Development Louisville, KY}

Graduate Assistant,

August 2013-

July 2016

Served as assistant to the chair of the departments of Middle Secondary Education and Special Education. Worked on program development, program accreditation, faculty and student interviews, and personnel selection, conference preparation, and research projects. Also served as a primary instructor for undergraduate developmental psychology course for one year.

\section{Research Productivity}

\section{Manuscripts}

Hooper, L. M., \& Idigo, K. C. (In progress). Discrimination and health outcomes.

Hooper, L. M., Tomek, S., Jaggers, J., Idigo, K. C., Church, W. T., Williams, J. \& Bolland J. (2017). Changes in self-reported levels of traumatic stress before and after a suicide attempt: A 14-year longitudinal study. Journal of Mental Health Counseling, 39(3), 242-262.

Kohn-Wood, L.P., Hooper, L. M., Smith, L., Idigo, K. C. , Haynes, T., Orr, T. \& Hudson, G. (In revision). The moderating effects of race on ruminative responses and depressive symptoms.

Owen, J., Drinane, J., Idigo, K. C., \& Valentine, J. (2015) Psychotherapist effects in meta-analyses: How accurate are treatment effects? Psychotherapy, 52(3), 321 328.

\section{Conference Presentations}

Idigo, K. C., (2017, March). The Nigerian-American experience: A story of resilience. Poster presented at the Great Lakes Regional Counseling Psychology Conference, Muncie, IN.

Watterson, K., Idigo, K.C., \& Visalli, K.M. (2017, March). Challenges for counseling psychologists in working with vulnerable populations in restrictive settings. Roundtable discussion presented at the Great Lakes Regional Counseling Psychology Conference, Muncie, IN. 
Idigo K.C., \& Owen, J. An in-depth look at therapy outcomes for racial ethnic minorities: Examining the role of micro-aggressions and racial/ethnic identity. Poster presented 8/2015 American Psychological Association, Society for the Scientific Study of Ethnic Minorities, Toronto, Canada.

\section{Outreach/Service}

\section{Louisville Urban League}

Women Engaged: Facilitate monthly conversation groups designed to reduce mental health stigma in the African-American community. Lead groups that encourage community members to explore the nature of relationships across various life domains and its impact on well-being. 12/2015- present

\section{University of Louisville}

Participated in a variety of outreach activities at the university tailored to address multicultural issues on campus. Disseminated relevant social justice literature to academics, administrators and students. Also partnered with the theater department to provide debriefing, and emotional processing to participants of Tunnel of Oppression an interactive experience designed to increase awareness of discrimination and systemic barriers to success on campus. I was also part of a team that hosted a self-care fair on campus aimed to improve well-being of students, and raise awareness of mental health services available to students. Also developed relationships with referral sources for department clinics to increase awareness of free mental health services offered by clinic. Additionally, I was active in my department as an applicant interviewer for our doctoral and master's programs. I served as the president of the doctoral student organization, where I organized monthly research talks, hosted guest speakers, and provided professional development to doctoral students.

University of Louisville Cardinal Success Program

Mental health presenter: Healthy Families Series, St. Ditmas Charities, 12/2015$4 / 2016$

University of Louisville Counseling Center

Organizer/Facilitator: Self-care fair, 4/2016

Group facilitator: Tunnel of Oppression debriefing group, 4/2016

Facilitator: Call Me Crazy/Love is Louder Movie Screening Event, 11/19/2013

Screener: Mental Health Awareness \& Suicide Screenings, 10/3/2013

Department of Educational and Counseling Psychology

President: Doctoral Student Organization, 4/2014- 5/2015

Public Relations Officer: Doctoral Student Organization, 1/2014- 5/2014

Event Coordinator: Faculty/Doctoral Student Social, Spring 2014

Interviewer: Master's program applicants, 2/20/2014 \& 3/27/2014

Member: Diversity Committee, 9/2013- 5/2014 
Anne Braden Institute for Social Justice Research

Panelist: Anne Braden Memorial Lecture Preview, 10/2/2013

\section{Cultural Center}

Facilitator: Let's talk Lunch series- Scapegoating/group dynamics, 9/2013

\section{Bellarmine University}

Provided training to peer educators a mental health organization on campus designed to provide psycho-education to student population. Taught basic helping skills, and recognition of crises situations warranting referrals. Also provided training on cultural sensitivity in treating African immigrants to nursing students. Facilitated workshop on stress-management for nursing students, as well as college-transition for freshmen athletes.

Consultant/Trainer: Peer Educators, 11/2014- 1/2015

Panelist/Trainer: Transcultural Nursing, 10/2014

Presenter: Stress management Workshop for Nursing Students, 9/2014

Presenter: Transition to College for Freshman Athletes, 1/2015

\section{American Psychological Association}

Served on various committees on APAs divisions. Role consisted of disseminating information related to the division's mission to the student body, and strengthening membership. I shared information on conferences and workshops related to multiculturalism and international psychology.

Committee Member: Divison 45 Ad hoc policy committee 8/2014- 12/2014

Campus Representative: Division 45, 2014-2016

Campus Representative: Division 52, 2013- 2014

Psychology Advocate: Advocacy Training Day (Psychology on the Hill), 8/2014

\section{Center for Modern Dance Education, Hackensack, NJ}

Served on the board of the non-profit dance studio. The mission is to make the Art of dance accessible to children regardless of ability level, size, and socio-economic status.

Member: Board of Trustees, 2009-2013

\section{Carmel Shelter, Haifa, Israel}

Volunteered at shelter serving immigrant and refugees in Haifa Israel. Provided positive activities for children, engaged in cultural immersion, and discussions related to religion and culture.

Volunteer: Saturday Worship 6/2012

\section{Community Center, Lod, Israel}

Taught English to leaders of a community center in Lod, Israel, an organization that serves low income residents.

English Tutor: Community garden leaders 6/2012 


\section{Teaching Experience}

\section{Instructor}

EDTP 107 Human Development \& Learning, Fall 2014- Spring 2015

\section{Guest Lecture}

ECPY 629 Theories and Techniques of Counseling \& Psychotherapy: Brief Dynamic therapies Affect Phobia, 11/2015

ECPY 629 Theories and Techniques of Counseling \& Psychotherapy: Brief Dynamic therapies Affect Phobia, 4/2015

ECPY 673 Practicum in Counseling Psychology/Internship in Counseling: Working with resistant clients, $6 / 18 / 2014$

ECPY 507 Learning \& Human Development: Socialization, Self-Concept, Identity, \&

Peer Relations, 5/22/2014

ECPY 629 Theories and Techniques of Counseling \& Psychotherapy: Special Topics

Multicultural Issues \& Challenging Clients, 4/14/2014

EDTP 107 Human Development \& Learning: Physical Development, 1/9/2014

EDTP 107 Human Development \& Learning: Family, Community \& Culture, 1/16/2014

EDTP 107 Human Development \& Learning: Learning \& Behavior Theories, 3/20/2014

\section{Teaching Assistant}

ECPY 673 Practicum in Counseling Psychology/Internship in Counseling, Summer 2014 ECPY 629 Theories and Techniques of Counseling \& Psychotherapy, Spring 2014

\section{Awards/Grants}

APA/APAGS Award for Distinguished Graduate Student in Professional Psychology (\$2,500) Awarded August, 2019

University of Louisville, Graduate Student Council, Research Grant (\$500) Awarded November, 2017

Psychotherapy Most Valuable Paper of 2015, American Psychological Association, Society for the Advancement of Psychotherapy, (\$500)

Awarded August, 2016

University of Louisville, Graduate Student Council, Student Travel Grant (\$250) Awarded Spring, 2014

University of Louisville School of Interdisciplinary Graduate Studies, Dean's Reception Professional Development Award (Certificate) 
Awarded Spring, 2014

\section{Professional Development}

Kentucky Psychological Association, Borderline \& Narcissistic Personality Disorder: Assessment, Treatment and Practical Skills. Dr. Eric Russ, 9/15/2017

University of Louisville, Grawmeyer award in Psychology talk. Dialectical Behavior Therapy: Where We Are, Where We Were, and Where We're Going. Dr. Marsha Linehan, 4/20/2017.

Mindsight Institute, Interpersonal Neurobiology \& The Clinical Implications of the Adult Attachment Interview. Daniel J. Siegel, M.D. 12/7/2016.

Assessing for Cognitive Impairment in Correctional Settings. Dr. Anne-Marie Kimbell, Pearson Clinical Assessment, 10/27/2016.

Providence House Self-Sufficiency Ministries, Bridges out of Poverty: Strategies for Professionals and Communities. 10/5/2016.

Providence House Self-Sufficiency Ministries, Sandtray Therapy Training. Dr. Liz England, 9/7/2016.

Complex Post Traumatic Stress Disorder \& Dissociation: A treatment Overview. Dr. Courtois, Kentucky Psychological Association, Fall 2016 Convention.

Opportunities in Psychological Practice: Reproductive Psychology. Dr. Greenamyer, Kentucky Psychological Association, Fall 2016 Convention.

Medical University of South Carolina, National Crime Victims Research and Treatment Center An On-line Training Course for Trauma-Focused Cognitive-Behavioral Therapy. 7/10/2016.

University of California, Davis, Children's Hospital, Parent Child Interaction Therapy for traumatized Children, Web Course. 9/10/2016.

Indiana Child Welfare Education \& Training Partnership, 2013 LGBTQ Youth Initiative, 9/9/2016.

University of Louisville, University of Louisville Counseling Center, Impact of Suicide Training. 11/2015.

University of Louisville, Cardinal Success Program @ Nia Partners for Change Outcome Management System (PCOMS) Training. 10/2015. 
American Psychological Association, Society for the Psychological Study of Social Issues, Advocacy Training Day, Washington D.C. 8/6/2014.

University of Louisville, Psychological Services Center, Solution Focused Therapy Workshop. 5/30/2014.

University of Louisville, Center for Mental Health Disparities, Diagnosis and Assessment of Obsessive Compulsive Disorder. Dr. Monnica Williams, 5/1/2014.

University of Louisville, College of Education and Human Development Instrument Development. Dr. Betsy McCoach, 3/28/2014.

University of Louisville, School of Interdisciplinary and Graduate Studies, Grant writing academy. Spring 2014.

University of Louisville, Center for Mental Health Disparities Psychopathology of Disgust in Contamination based OCD, Cross cultural explanations. Dr. Bunmi Olatunji, 10/2013.

\section{Research Teams}

Resilience Research Lab

September 2016- present Dr. Laurie McCubbin, Associate Proferssor of Psychology, Department of Counseling and Human Development, University of Louisville, KY Conduct studies evaluating resilience across various ages and cultural groups. Particular attention to the operationalization and conceptualization of resilience, and cross-cultural invariance of resilience measures. Testing models of family resilience including the double ABCX model of resilience and the Trauma Adaptation and Stress model.

\section{Relationships and Psychotherapy Lab}

January 2014- July 2014

Dr. Jesse Owen, Associate Professor of Psychology, Department of Educational and Counseling Psychology, University of Louisville, Louisville, KY

Study multicultural competencies in counseling, and stigma associated with mental health among underserved groups. Conducted psychotherapy research aimed at advancing clinical interventions. Conduct literature reviews, analyze data and prepare manuscripts for publication.

\section{Research Assistant}

Dr. Samuel Juni, Professor of Psychology at the Department of Applied Psychology, Steinhardt School of Education, New York University, New York, NY Conduct literature reviews, analyze and code data, maintain accurate records of interviews, safeguard confidentiality of subjects attend project meetings, summarize project results. 
Clinical Research Volunteer

September 2011- March 2012

Dr. Mary Sano's Alzheimer Disease Research Center, Department of Psychiatry, Mount Sinai School of Medicine, New York, NY

Assist in recruiting participants, administering and scoring assessments, and presenting clinical cases to a team of researchers and medical professionals.

\section{Senior Research Project}

Idigo, K.C., \& Mesidor, L. (2006, May). Binge-drinking Among College-aged Students. Qualitative research project completed at Temple University, Sociology Department, Philadelphia, PA.

\section{Research Interests}

Multicultural competence

Immigration and International Psychology

Social Justice/Advocacy/Community Intervention

Resilience and Well-being

Religion/Spirituality

\section{Related Experience}

\section{New York University, Department of Applied Psychology}

Tel Aviv, Israel

Cross-Cultural and Group Dynamics in Stressful Environments May 2012- June 2012 Earned 6 graduate level credits in Cross-Cultural Psychology and Group Dynamics while studying various ethnic and religious groups in Israel. Experienced the full spectrum of group and cross-cultural dynamics by studying religion, politics, ethnicity, ability, gender, level of education and socio-economic status and its role in various groups. Through guest and faculty lectures, seminars with Israeli Psychology graduate students and local leaders and site visits students gain further insight into the lifestyle and culture of various groups. We explored the effects of immigration and acculturation on personal and group identity formation by participating in process-based group activities. We also developed a heightened level of self-awareness and explore conflict-resolution at an intrapersonal, interpersonal and inter-group level.

\section{City University of New York, Office of Admission Services}

New York, NY

Admissions Counselor

September 2008-May 2012

The City University of New York is the largest public university system in the United States. The university serves 220,000 undergraduate degree seeking students. To achieve this goal the university provides traditional educational services, as well as mental health services aimed to foster student development and success. Responsibilities included giving presentations to recruit incoming freshman and transfer class, conducting application workshops, conducting individual and group sessions with prospective students, explaining the U.S. educational system to students educated abroad, review application materials to determine proper fit across the university system, make referrals to appropriate student services, working with students in the career exploration process 
and assisting in developing educational plans. In addition I developed a role-play which has been used to teach new counselors effective communication skills, and the use of assertiveness when dealing with difficult students.

\section{Care Resources Incorporated}

Baltimore, MD

Substitute Special Educator

September 2006- June 2007

Care Resources Incorporated is a non-profit organization that provides support services to students with physical and cognitive disabilities. Services include special education, physical and occupational therapy and psychological services. Responsible for instructing students with special needs with the use of accommodations and modifications, designing Individualized Educational Plans and daily lesson plans, and facilitating the transition of self-contained students into a mainstream educational environment.

\section{Temple University, Institute for Survey Research}

\section{Philadelphia, PA}

Interviewer

October 2005- May 2006

The Institute for Survey Research is one of the highest regarded academic survey centers in the country. It has over 40 years of experience conducting national, state and local surveys, needs assessments, focus group research, statistical research and program evaluation. ISR collaborates with faculty and researchers across a broad range of topics and fields. Responsibilities included conducting telephone interviews on national and local surveys, providing feedback on the response of interviewees, recording data collected with the use of Computer Assisted Telephone Interviewing software and maintaining contact database.

Director: Leonard LoSciuto Ph.D., Supervisor: Renee Larson, M.S. 